\title{
The Evaluation of Construction Waste Management in Northern Cyprus
}

Milad Najafy

\begin{abstract}
Submitted to the
Institute of Graduate Studies and Research

in partial fulfillment of the requirements for the degree of
\end{abstract}

Master of Science

in

Architecture

Eastern Mediterranean University

September 2014

Gazimağusa, North Cyprus 
Approval of the Institute of Graduate Studies and Research

Prof. Dr. Elvan Y1lmaz Director

I certify that this thesis satisfies the requirements as a thesis for the degree of Master of Science in Architecture.

Prof. Dr. Özgür Dinçgürek

Chair, Department of Architecture

We certify that we have read this thesis and that in our opinion it is fully adequate in scope and quality as a thesis for the degree of Master of Science in Architecture.

Asst. Prof. Dr.Ercan Hoşkara

Supervisor

Examining Committee

1. Asst. Prof. Dr. Halil Z. Alibaba

2. Asst. Prof. Dr. Polat Hançer

3. Asst. Prof. Dr. Ercan Hoşkara 


\begin{abstract}
It is universally agreed that the modern construction is immensely bounded with waste management and waste minimization as it contributes to an increase in construction and post construction expenses in order to collect, handle, transport and transfer waste materials.
\end{abstract}

In this study, the current situation of waste management in Northern Cyprus and more specifically the situation in of Famagusta are analyzed. In addition, available governmental codes and regulations were taken into account and the implementation of the aforesaid regulations was investigated.

The most important problem behind the waste management system being ineffective was established to be the lack of awareness among different members of industry about advantages of waste reduction and disadvantages of a defective system.

In Northern Cyprus, there is minimal technology available for recycling materials such as paper recycling and mostly reusing methods for on-site construction. Therefore, the most efficient resort to enhance the current situation of waste management in construction industry of Northern Cyprus, is to minimize the generated waste, or to try to use materials which could be reused on construction site.

As the result, weak areas were highlighted and suggestions and recommendations were made in order to enhance the waste management system and to reduce the generated waste. 
Keywords: Construction Waste Management, Construction Waste Minimization, Northern Cyprus, Residential Construction, Architectural Design 


\section{ÖZ}

Çağdaş inşaatın atık yönetimi ve atıkların en aza indirgenmesi ile bağdaştırıldığ dünyaca kabul edilen bir algıdır. Atıkların toplanması, yönetilmesi ve taşınması inşaat sürecinde ve inşaat sonrasındaki harcamalarda büyük rol oynamaktadır.

Kuzey Kıbrıs’ta; geri dönüşüm için kullanılabilecek teknoloji düşük bir seviyededir. $\mathrm{Bu}$ sebeple, Kuzey Kıbrıs inşaat sektöründeki atık yönetimine en çok yardımcı olabilecek çare, inşaat sürecinde üretilen atık madde miktarını en aza indirgemek ve tekrardan kullanılabilen maddeleri tercih etmek olacaktır.

Bu çalışmada, Kuzey Kıbrıs'ın Gazimağusa şehrindeki atık yönetiminin güncel durumu analiz edilmiştir. Ek olarak, devlet tarafindan oluşturulmuş yasalar dikkate alınarak, ilgili yasaların uygulanışı da incelenmiştir.

Atık yönetimi sisteminin etkisiz oluşunun altında yatan en önemli sorun, farklı sektörlerin etkili bir yönetimin faydaları ve kötü atık yönetiminin zararları hakkında gerekli farkındalık bilgisine sahip olmayışıdır.

Sonuç olarak, zayıf alanların altı çizilmiş ve üretilen atık miktarını azaltarak, etkili bir atık yönetimine sahip olmak için yapılması gerekenlerin altı çizilmiştir.

Anahtar kelimeler: İnşaat atık yönetimi, inşaat atıklarının en aza indirgenmesi, Kuzey Kıbrıs konut inşaatı, mimari tasarım, süreklilik. 


\section{DEDICATION}

To My Family 


\section{ACKNOWLEDGEMENT}

Foremost, I would like to express my sincere gratitude to my family for all of their support and kindness

I want to thank my supervisor for the continuous support of my master study and research, for his enthusiasm and motivation. His supervision has governed me in all the time of research.

My sincere thanks also go to all my friends who have helped me finish this thesis. They were available for me whenever I needed something from them. 


\section{TABLE OF CONTENTS}

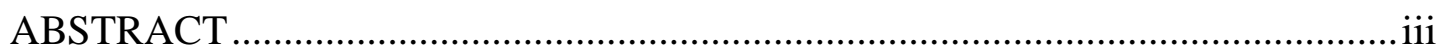

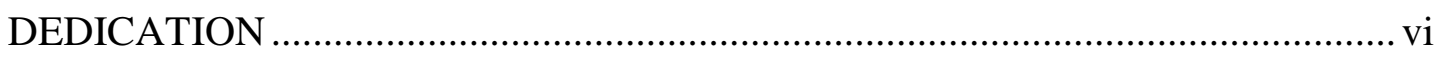

ACKNOWLEDGEMENT …................................................................... vii

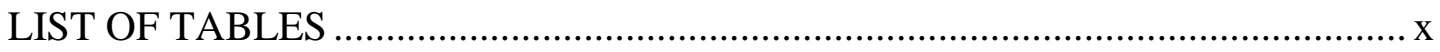

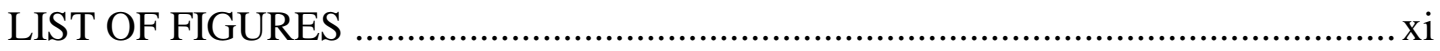

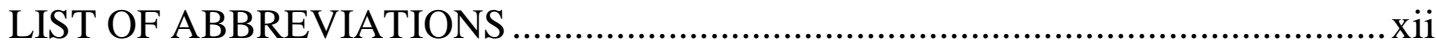

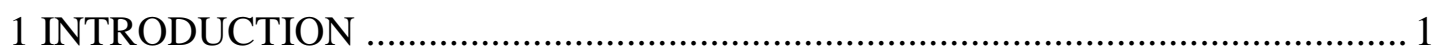

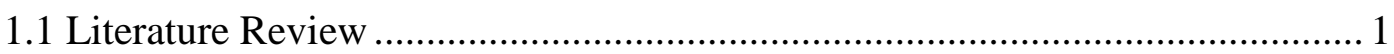

1.2 Problem Statement and Significance of the Problem .................................... 4

1.3 Aim of the Study, Research Question, Scope and Objectives.......................... 5

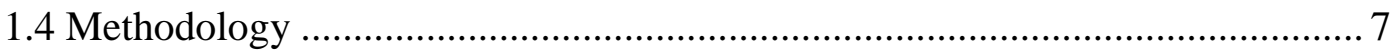

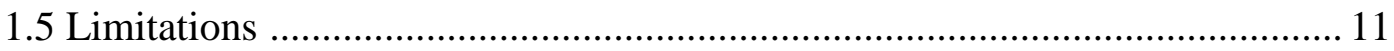

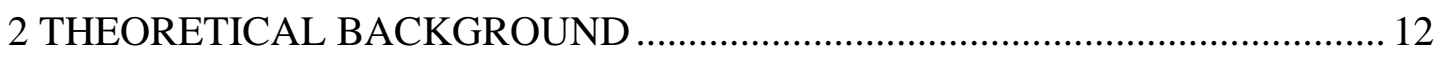

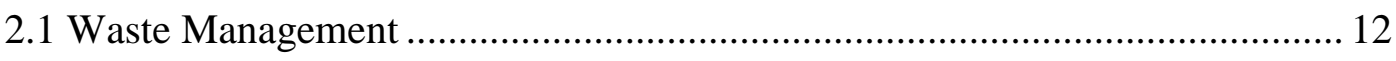

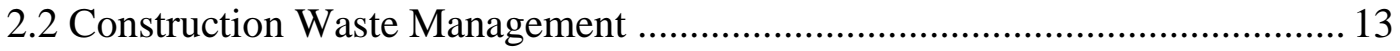

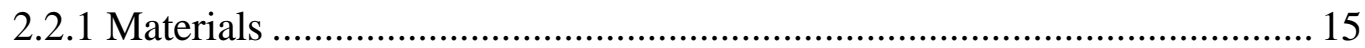

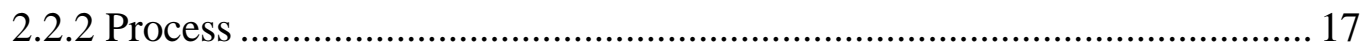

2.2.3 Facility Design ................................................................................. 24

2.3 Stages of Construction Waste Management................................................ 27

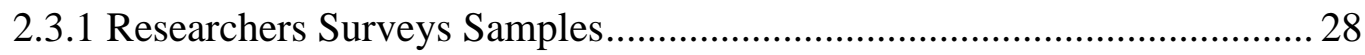

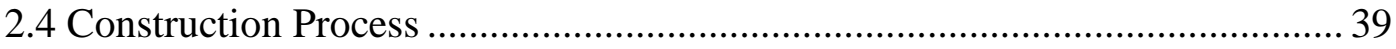

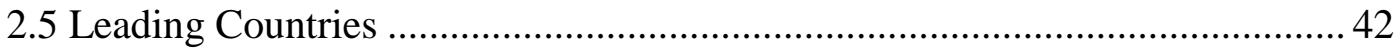

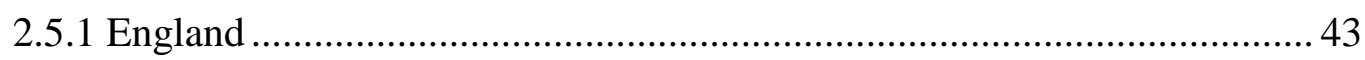


2.5.2 Australia.

2.5.3 Canada

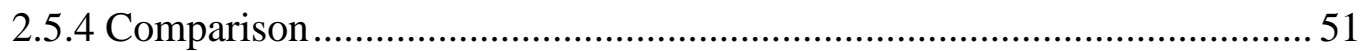

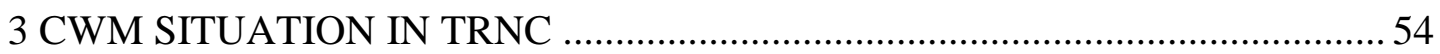

3.1 Introduction to the Northern Cyprus and Famagusta .................................... 54

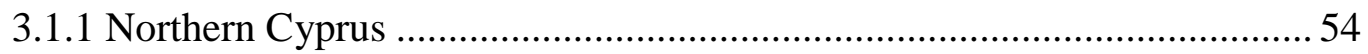

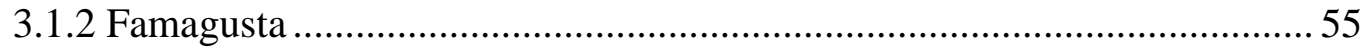

3.2 Current Situation of Material and Waste Material in Northern Cyprus ....... 56

3.3 Current situation of waste management in North Cyprus ........................... 61

3.4 Results of Analysis on the current situation of C\&DWM in the Northern

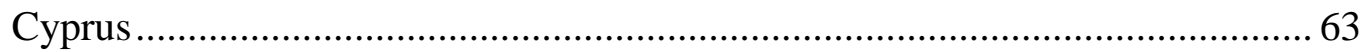

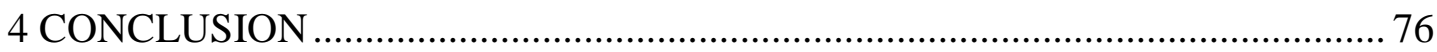

4.1 Suggestions for Future Research and Investigation .................................... 84

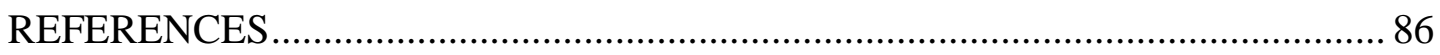

Appendix A: The Interview Form …......................................................... 90

Appendix B: Summary of C\&D Related Legislation ........................................... 96 


\section{LIST OF TABLES}

Table 1. Comparison CWM (Construction Waste Management) 64

Table 2. CW Generated by Resource Consumption in Implementation of the CCM

Table 3. Conversion of Weight to Volume in Construction and Demolition Debris (For all types of structure)

Table 4. Suggestions for disposal method and handling procedure in construction projects 


\section{LIST OF FIGURES}

Figure1. Building Life cycle Phases............................................. 27

Figure 2. Avoid excessive ordering .............................................. 34

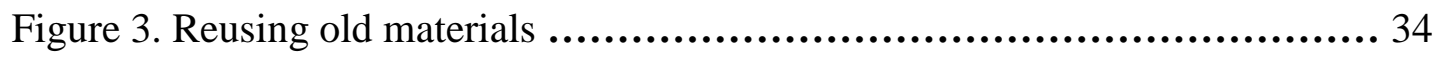

Figure 4. Packing and handling minimizes on site waste.......................... 35

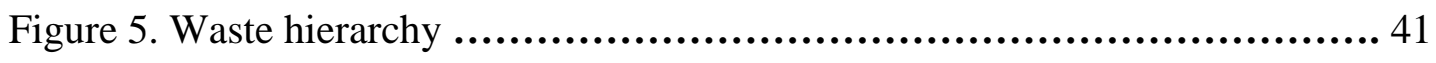

Figure 6. Cyprus Geographical Map.............................................. 55

Figure 7. Famagusta........................................................... 56

Figure 8. Mountains as sources for aggregates................................. 57

Figure 9. Unorganized waste disposal......................................... 58

Figure 10. Unorganized waste disposal......................................... 58

Figure 11. Mixture of different waste materials................................. 59

Figure 12. Mixture of different waste materials.................................. 59

Figure 13. Categories of participants......................................... 65

Figure 14. Waste material attribution to phases................................... 65

Figure 15. Activity share in waste generation.................................... 66

Figure 16. Material share of waste.............................................. 67

Figure 17. Priorities in construction ......................................... 68

Figure 18. Willingness to reduce waste......................................... 69

Figure 19. Reasons behind unwillingness to reduce waste generation.............. 70

Figure 20. Importance of steps................................................. 72

Figure 21. Factor effectiveness in implementing WMP........................... 73

Figure 22. Factor effectiveness in developing waste minimization ................. 74 


\section{LIST OF ABBREVIATIONS}

CHBA Canadian Home Builders Association

CWM Construction Waste Management

C\&DW Construction and Design Waste Management

CWMP Construction Waste Management Plan

DE Design for the Environment

PWGSC Public Works and Government Services Canada 


\section{Chapter 1}

\section{INTRODUCTION}

In the current chapter, previous researches and investigations in the field of construction waste management and minimization is taken into account, to benefit from findings of other scholars and implement the results of their research to broaden the limits of the available knowledge in our case study of Famagusta.

Besides, Available regulations and laws which are being implemented in pioneer countries in this industry is investigated and summarized, to be able to propose solutions to improve the current condition in our case study, and highlight the shortcomings.

\subsection{Literature Review}

It is universally agreed that the modern construction is immensely bounded with waste management and waste minimization as it contributes to an increase in construction and post construction expenses in order to collect, handle, transport and transfer waste materials.

Even if materials are totally recycled after or during the construction, regardless of transportation, collection and handling fees, noticeable amounts of money must be spent to recycle materials. Therefore, it seems more logical to minimize waste in the first place so it is not needed to try to recycle or reuse great deal of materials. However, it is thoroughly unexpected that during the complete life-cycle of a 
construction process, even as small as a residential unit, waste materials are avoided (Napier, 2012).

To pursue the right approach to recycle or reuse construction materials, is another prominent step to be followed, in order to compensate for unnecessary expenses which had been invested on extra materials during the construction phase, or building elements after the life of the project is officially over.

There are several types of materials which are wasted during the construction of a house but, regarding the reuse and recycling issues, major waste materials fall into five different categories which account for approximately $80 \%$ of total construction phase (Environment and Energy, 2008).

First and foremost category is concrete and mortar which are the result of landing ash, dabbing and cut pile heads, concrete and rest mortar and open holes and formwork leakage in construction site. Concrete and mortar are stated to be the largest category amongst (CHBA, 2010).

Second category which in term of the amount, lags behind concrete and mortar is bricks and clocks category which are the result of damage in construction, damage in delivery and removal for changes and disqualifications (Napier, 2012).

Lumber and formwork on the other hand, is the third category. Special shaped formwork and expiration of formwork are the main reasons behind the generation of these types of construction waste. However, the role of off cuts, cannot be neglected and as the matter of fact is quite comparable to the other two (Napier, 2012). 
Fourth category is fencing bricks and tiles. The responsible factor for this type of waste is generally damages in delivery and discharge, as well as removal for changes and inferior quality. Off cuts likewise, contribute to this category to a great extent (CHBA, 2010).

The last category which popularity is roughly the same as the forth category, is the steel bar and other metals which are generated because of surpluses of steel bars which are produced by blanking, sheared steel bars and blots through walls (EdgeEnvironmentPtyLtd, 2011).

There are several reasons behind the generation of construction waste and the most important one is not implementing a proper waste management measure and not being aware of saving materials and protection of the environment.

In addition, lack of supervision on construction sites is another important factor and should be encourages not only by owners of projects, but also by contractors and project managers. Besides, short of communication and coordination between different managers and contractors, as well as between contractors themselves, can lead to an increase in the amount of waste produces (HyderConsultingPtyLtd, 2011).

Moreover, in addition to the factors related to human knowledge and performance on the construction sites, economical facts and material physical facts somehow would be able to dominant human mistakes and low performances. For instance, if the discharge fee of waste is comparatively negligible which in most cases is, recycling option cannot be encourages easily (EdgeEnvironmentPtyLtd, 2011). 
Another example of similar factors is the low performance of construction materials which is a major source of waste generation in some cases. It was established that traditional building materials can produce nearly $80 \%$ of construction waste. Waste management comprises three main parts namely recycling, reuse and deconstruction. In developed countries with signification technologies in the field, the process of recycling is carried out regularly and efficiently. Hence, it is possible to demolish the building and benefit from the solid waste as it could be undergone various recycling methods (HynderConsulting, 2011).

Reusing on the other hand, depends on the demolition technique as well as the type of materials and building elements used in the building and the installation method. Normally, materials are used again in the construction of new buildings without going through a recycling process (Environment and Energy, 2008).

In addition, deconstruction is carried out prior to the demolition of building. A detailed investigation is carried out on the remaining building elements and even furniture and the usable ones are separated. The attributed savings for deconstruction can be increased significantly if considered at the design stage so reusable elements and materials are used in the building, and a noticeable rise could be happening for the salvage value of the building (Environment and Energy, 2008).

\subsection{Problem Statement and Significance of the Problem}

In Northern Cyprus, compared to the population, there are a vast volume of construction waste annually and there is not a proper waste management condition exist in the industry so most of the waste from construction is dumped into the existing landfills similar to the solid municipality waste. 
Besides, apart from plastic and paper, there are no significant recycling technologies to be applied to the construction waste in order to increase the salvage value of the building. Hence, the only options left are reusing and deconstruction which seem to be comparatively more beneficial for the industry. The aforesaid options are to be investigated in the current study.

Furthermore, it should be taken into account that after the demolition, to apply reusing techniques to the remains, need proper technology, as the result of which it seems more logical to invest the time and effort on the possible improvements of deconstruction measures at the design stage as well as the construction phases of residential construction.

The dominant construction material which is being used in the current residential construction industry of Northern Cyprus is concrete. A very important problem regarding the production of concrete is providing aggregates in different sizes to be mixed with cement in order to produce concrete.

\subsection{Aim of the Study, Research Question, Scope and Objectives}

The main aim of this study in to investigate the existing construction waste management condition in Northern Cyprus and possibilities to improve it.

To achieve this goal, in comparison with proper codes and regulations in other countries, the existing codes in Northern Cyprus are analyzed and shortcomings are highlighted.

Finally, missing elements in the design from point of view of architects and civil engineers, construction phase from the point of view of supervisors, construction 
managers and contractors phase from the point of view of waste management condition are highlighted and defined. Conclusions are drawn and recommendations for additional design and supervision codes for a proper waste management condition which conform the specific situation of the island is made.

Considering the provided problems and significance of study, the question which will hopefully be answered as the result of the current investigation could be summarized to:

What is the existing condition for construction waste management in Northern Cyprus and how it can be improved?

Current investigation principally focuses on proposing measures to be taken at the design stage of residential units as well as at the construction stage phase, which will lead to waste minimization and reusing the waste as the result of deconstruction.

Accordingly, the objectives are presented in chronological order below:

1- To analyze the current situation of construction waste management system in Northern Cyprus.

2- To analyze regulations and codes for construction waste management in the residential construction industry of Northern Cyprus.

3- To come across missing elements amongst construction codes as well as available construction waste management on the Island. 
4- To investigate on the applicability of missing elements according to the available technology and the feasibility of different options.

5- To make recommendations to be applied at the design stage, at the construction phase and at the demolition phase of a typical residential dwelling, in order to minimize the construction waste of the aforementioned residential unit.

6- To suggest codes and regulation to be added to the existing residential construction codes, so the application of suggested measures is easier to be applied in every case.

\subsection{Methodology}

Interviews are extremely important tools for data gathering by which they make it possible for researcher to collect and extract the beliefs and perceptions of individuals as well as their expression of their past experiences and feeling. There are two most important categories of interviews. They could be either structured or unstructured. Normally, interviews comprise several types of questions regarding a specific research question which is divided into several coherent parts as smaller questions. Types of questions depend on the subject as well as the target group of individuals who are supposed to complete the interview session or survey.

\section{Result of Interviews}

One of the most important factors affecting the percentage of returns is the length of interview session. As an interview session is designed longer, required motivation to finish it would be increased drastically. Besides, designing an interview include more restricted than open types of question, would motivate individuals to finish the survey completely to the end, as the answers are presented and they do not have to 
form sentences, and they regardless of the number of questions, it is perceived by them that they can go through questions and finish them more quickly than open question types in the survey.

The second factor affecting returns is the time of the year at which interview sessions are carried out. One who is busy which tight schedules before the New Year holidays, is not predicted to have spare time for interviews and the validity of answers could easily be questioned in such periods throughout the year.

The sophistication of presented questions in an interview session is another affecting factor on the percentage of return. It is expected that a response is only as comprehensible as the question asked. Besides, it is not always expected that one is present at the time of completing an interview session to clarify questions for individuals, in case of the complexity of interview or a specific question, it is foreseeable if a subject present a vague response or even decide to skip the question.

Another important factor is the reputation of the company or organization which sponsored the research or carried out interviews. If the sponsored organization behind the interview session is a famous company with proper reputation, it is established that respondents are more motivated to complete interviews.

Another subjective factor is the significance of the study for carrying out which the interview was carried out. The importance is determined not only by the company behind the research, but also and more significantly by the respondent him/herself. The more important the respondent suppose the investigation is, the higher percentage of completed interviews is in a survey. 


\section{The Interview}

There are several types of question which are going to be asked by the interviewer from different categories of interviewees.

The aim of forming interviews and asking the following questions is to figure out the information level of different participant at diverse stages of construction and different sectors which could be related to a construction project at different stages. What participants believe to be important in the waste management process can give an idea of real and practical issues in the process. Obstacle which may be mentioned by participants could not be forecasted in theory and are valuable resources of information for future considerations.

In addition, an uneducated category in terms of waste management, could be a considerable drawback in the process and by asking the following questions, the level of information is uncovered at each category, and weak areas are highlighted. By educating the weak areas, the efficiency of waste management condition could be maximized.

More specifically, considering detailed questions, the possibility, problems and improving suggestions for reuse or recycle materials and more importantly, reducing the generated waste are highlighted and investigated. Focusing on each phase and each category of participants, after performing the analysis on collected answers, suggestions for future improvements could be drawn and be presented. 
Every single category is a member of construction industry in term of generation or management of construction waste and plays a significant role in creating or managing the waste.

The aforesaid participants are divided by the phase of a construction life cycle as well as the role that is played by each. The foremost participants are designers which can be divided into 3 types of architecture design, structural design and map design. It is established that the effect of a proper design in which the possible waste materials are forecasted and minimized is exceptional.

The second important category is the authorities category which could play a significant role in waste reduction by issuing related regulations and force other participants specially contractors and project managers to follow instructions in order to reduce waste materials. Besides, by providing technology, they can make solutions for recycling materials feasible. In the current study, Municipality of Famagusta, the central government and environmental board are going to be interviewed.

The third category is contractors which are conventionally believed that will follow the limitations, regulations and restrictions if they exist in the industry. Their motivations and problems with regard to waste management is going to be analyzed by means of the correct interview. For this study, Northernland, Noyanlar and Onlar construction companies are going to be interviewed.

The final category is the category of material providers which are believed to have the least impact on waste management. However, if the proper technology exists they 
may be able to re-buy the extra materials from contractors and transfer it to the factory.

The generated interview form is attached to the thesis in appendix A.

\subsection{Limitations}

The current study is limited to the residential construction in Northern Cyprus, and the city of Famagusta was chosen as the case study and the representative of conventional element of the industry. 


\section{Chapter 2}

\section{THEORETICAL BACKGROUND}

In this chapter, the countries that are leading samples in the waste management implementations are mentioned and their evolution process in waste management and codes and regulations which are being used at the moment for each country is illustrated. This section will be used for comparison purposes to the current situation in Cyprus and providing suggestions and recommendations for future progress.

Finally, previous research that has been done regarding construction waste management are mentioned and important parts of their study, conclusions and recommendations are highlighted.

\subsection{Waste Management}

In this section, previous important investigations regarding the $C \& D$ waste management is highlighted and the valuable results of their research are accounted for.

There has been noticeable amount of studies and published literature on C\&D waste management and according to an analytical study by Shen \& Yuan (2011) the interest trend for the research in this field has been upwards. They also reported that the contribution of researches from developed countries was comparatively high; however, two major countries from the developing category namely Malaysia and 
China demonstrated growing interest in the field and has been carrying out research to a considerable extent.

The majority of research in this specific chose surveys and reviews as the methodology for their research as most of the research performed focusing on case studies. The analysis method of the collected data via the aforesaid method reported to be descriptive (Shen \& Yuan, 2011). On the other hand, less authors chose simulation modelling and statistical analysis for their investigation, and least researchers chose cost benefit analysis as the method for their investigation, they reported.

They concluded that future research in this field of study would be carried out in developing countries as their prominent activities from the point of view of economics would be in construction industry.

\subsection{Construction Waste Management}

Waste management is a broad concept and conventionally implies the process during which waste materials as the result of the activities by human being is collected from generation points and transferred to destination for the purpose of disposing or being made use of.

The scale of waste generation depends on the sector within which the waste material is generated, namely residential and industrial, the activity as the result of which waste is generated, such as municipal activities, construction or industrial activities, and the process during which the waste is managed is attributed to the each type of activity. 
In this chapter, initially, the waste management in construction industry is defined, the normal materials that are conventionally generated as the result of construction and demolition activities are categorized and overall process which is normally carried out for managing this type of waste is explained and steps are accounted for in order to make the waste management plan clear.

Construction waste management $(\mathrm{CWM})$ by definition is to eliminate the waste material if there is no other options, to recycle the waste material in the case of being feasible, and to reuse the material which would become waste if they are not reused.

The main objective of construction waste management is to apply these solutions where possible, to accomplish sustainable management of construction materials and resources which could also be time and workforce.

The importance of the implementation of CWM is that in the majority of countries, waste materials are disposed in landfills according to law and regulations, as well as in areas where it is against the law to dispose construction and demolition waste. Not only are these disposals against the law, but also they damage the environment and they impose adverse effects on human health and commercial matters in case of disposing in illegal and badly designed landfills (Napier, 2012).

Construction and demolition waste can also be separated from the waste stream and the procedure through which these materials are set aside is called diversion and the materials are called diverted materials. The amount of aforesaid materials is a dependent factor to several factors amongst which the most important ones are 
"macroeconomic conditions affecting construction, societal consumption trends, and natural and anthropogenic hazards" (Napier, 2012).

A considerable amount of construction waste is produced at the level of small scale projects, which in most of the countries are subject to regulations of local government and municipality. It was reported by Napier (2012) that the management of waste materials are influenced by several factor such as:

- Whether a proper place for disposing materials is availableor not

- The overall condition of the economic situation of the country or state

- Societal priorities

- Whether or not there is a viable market available for recycling and reusing materials

- Transportation options

\subsubsection{Materials}

There are three most important stages at which waste management could be implemented. At project level to which the majority of waste materials are attributed, at organizational level and disposition level. In each stage the material is considered important, since the usage, and reuse of it will be effective in generating C\&DW plans.

There is a very important step to be taken prior to the development of a management plan, using all extra materials during the construction and demolition process are efficiently managed. The step is to identify the materials which could be a part of the waste management plan, prior to the initiation of the project (Napier, 2012). 
For residential construction, there are typical materials that normally become waste, not only during the construction phase, but also after the life of the project is over. The aforesaid materials are listed below:

- Plastic

- Gypsum board

- Lighting fixtures

- Plant materials

- Masonry

- Rubble

- Glass

- Woody materials

- Doors

- Cardboard

- Asphalt roofing

- Wood

- Plumbing fixtures

- Concrete

- Carpets

- Windows

- Paper

- Ferrous metal

- Non-ferrous metal

- Rubble

- Aggregate (Different sizes) 
The accomplishment procedure for each waste management plan is directly depended on each project in terms of specifications and requirements. However, speaking of residential construction within a certain scale, a general requirements and specification could be defined, that includes a range of construction materials (Napier, 2012).

\subsubsection{Process}

The foremost step in managing construction waste materials is to identify them on the construction site and sort the according to the type, volume and priority. Taking this step would efficiently help the manager to prevent materials from disposition in landfills and would direct them to a more environmental-friendly solution (Cambridge, 2008).

In most developed countries in terms of waste management, there are regulations regarding construction waste materials. It is important to consider codes and regulation of the state or country in which the project is being constructed and mention them in contracts and subcontracts related to diverse section of construction (Laquatra \& Pierce, 2002).

Normally, there are companies, which provide services that contribute to waste management plan. These types of companies provide containers on the construction site in which waste materials could be collected and sorted. It should be noted that less containers are desired on the construction site as it is easier for the company to handle and it would occupy less space on the site. In order to reduce costs and decrease the number of trips, volumes of containers must be kept as high as possible (Laquatra \& Pierce, 2002). 
The next step is to transport containers to diversion facilities by means of trucks. For this purpose light duty and sometimes-medium duty trucks are utilized. The identification of waste materials in the facilities are very important as it contributes to the handling process to a noticeable extent. Typically, the accepted type of materials are defined and described in the facilities and if in any case some of unacceptable materials are transferred to these facilities, it is most probable that they are disposed in a landfill (Napier, 2012).

The next step of waste management process is picking and sorting. Materials are loaded on the floor from the containers and picked via loader machineries. Material sorting is performed normally with a belt that is inclined transferred through a sorting section in which there are several workers who identify different types of materials, separate them from the stream and gather them is specified container for each material. The sorting process is only as effective as the previous picking stage is, as for instance large materials would be very hard to handle if were not picked in the previous stage, and will as well decrease the productivity of the current process (Cambridge, 2008).

Separated materials are deposited in special industrial containers according to their types and compacted with special machineries to occupy less space. Compacted materials are then transported in intermodal containers that are specifically designed for shipping purposes. At this stage, heavy duty trucks are utilized in order to transport materials domestically, or regionally. Other means of transportation such 
trains and ships are used in order to transport materials in national or international scales (Cambridge, 2008).

Finally, materials that can be used for producing new products are recycles, those that can be process for using again in new products are reused and those that are contaminated with waste materials or there is no market for them available are disposed in landfills (Laquatra \& Pierce, 2002).

There are some criteria which should be considered for a landfill. Firstly performance criteria as per British Columbia ministry of environment, "the design and operation of landfills should reflect the 3 Rs of waste management, namely reduce, reuse and recycle. This translates to a philosophy that stresses preventing, or at least minimizing, the production of leachate and landfill gas" (British Columbia ministry of environment, 2014).

Second, regarding the quality of water, Landfills must not be operated in a manner such that ground or surface water quality in existing or potential future water supply aquifers or surface waters decreases beyond that allowed by the Approved and Working Criteria (British Columbia ministry of environment, 2014).

Finally, regarding the public health, a landfill must not be operated in a manner such that a significant threat to public health or safety or a public nuisance is created with respect to: unauthorized access, roads, traffic, noise, dust, litter, vectors or wildlife attraction (British Columbia ministry of environment, 2014). 


\subsubsection{The Value of Materials}

The proportions of each construction material that exist in the total waste stream is strongly related to the economic situation of the state or country at that moment and local priorities. For instance, in an area that wood is cheap and widely used for residential construction, it is expected that the majority of construction and demolition waste would be wood or wood-based. Another example is a district containing rather old buildings constructed with masonry materials, in which it is expected to observe considerable amounts of masonry in demolition total waste (Cambridge, 2008).

\section{Metal (Non-Ferrous and Ferrous)}

Amongst all construction and demolition waste materials, metal is comparatively valuable and the rate at with metal is diverted is the highest amongst others. Bigger pieces of ferrous metal is separated from concrete by the utilization of special excavation equipment. On the other hand, smaller pieces are separated by employing magnets over the sort line as well as workforce for manual separation (Laquatra \& Pierce, 2002).

Non-ferrous metal in which category is mostly aluminium, is collected with reverse magnet system, or similar with manual collection of ferrous metal, by using human workforce.

\section{Cardboard and Paper}

This category of materials is suitable for recycling; however, they are not as valuable as papers or cardboards, which are normally collected from curbsides. The reason is that paper and cardboard which is separated from construction and demolition waste 
is normally contaminated with dust, water and other materials, which are normally being found on the site (Cambridge, 2008).

\section{Plastic}

Considering plastic as a recyclable material is different from other waste materials; because, generally speaking, plastic cannot be recycle to the same materials with the same quality and the same type. Actually, plastic is down-cycled. One of the worst materials that are being found in plastic waste is plastic film. The reason behind the undesirability of plastic film is that the existence of this specific elements reduces the efficiency of picking process to a great extent. Normally, an impediment to recycle plastic is the comparatively low price of recycled product. A solution to this problem is to export waste plastic or using it for generating energy in combustion energy generation plants. Categories to which waste plastic could be recycles are polystyrene, polyethylene, polypropylene, polyvinyl chloride and polyethylene terephthalate (Laquatra \& Pierce, 2002).

\section{Wood}

Wood is a precious material for recycling specifically in districts where it can be found easily and for reasonable price. Wood construction is strongly related to the weather condition of a district, state or country as processing wood for making them ready to be used in residential construction is very expensive and time consuming, unless the district is humid throughout the year and wood needs not to be processed in which case it makes a perfect material for construction specially in residential sector and consequently, massive amounts of waste wood is found during the construction phase or after the demolition phase. The waste can be used to 
manufacture feedstock for biomass or it can be transferred directly to combined heat and power plant (Laquatra \& Pierce, 2002).

\section{Concrete}

Concrete is a predominant waste material and a very useful one for recycling in several countries. Concrete can be completely recycled with comparatively basic technology. After the picking process concrete is crushed and divided into two categories. The first category is metal which use to be embedded in the concrete and would be transferred to metal processing unit. The remaining concrete and rock part are then monitored and crushed to desired sizes for being used as aggregates for diverse desired purposes (Napier, 2012).

\section{IWS}

Amongst construction and demolition waste, there are always found which has no or very less economic value. If the size of these materials are less than 8 inches and more than 0.75 inches, they can be used as physical stabilizer of legal landfills (Napier, 2012).

\section{Aggregates and fines}

A noticeable share - almost one fifth - of waste materials is aggregates and fines. Small concrete pieces, rocks and smaller pieces of stones are in this category. They can be separated easily and reused as aggregated of desired sizes for diverse purposes in construction sites (Cambridge, 2008). 


\section{Window glass}

A comparatively small percentage of construction and demolition waste is window glass. The material is very hard to handle and its weight per volume is comparatively high, which means that the transportation of this material would impose additional cost to the project, or the company in charge of waste handling. Consequently, unless a special recycling unit is available within negligible distance of the construction or demolition site, window glass is disposed in landfills (Laquatra \& Pierce, 2002).

\section{Carpeting}

The importance of putting effort to reuse carpeting material is that the production process of new carpeting materials contributes to the emission of greenhouse gasses. Waste carpeting is a very hard material to pick and sort, as there are a few changes to recover materials of high values. Carpeting materials are collected from stockpiles conventionally and transferred to manufacturers, which can use their fibre in the production process of new materials (Cambridge, 2008).

\section{Drywall}

Similar to carpeting, gypsum is very hard to handle in terms of picking and sorting. Besides, the unusual amount of dust during the handling process is uncomfortable for workforce and reduces their productivity. In addition, the dust decreases the quality of separated waste materials, which are going to be recycled. The outcome can be used in the production of new drywalls or for improvement of the quality of soil (Cambridge, 2008). 


\section{Asphalt roofing}

Waste asphalt can be grouped according to the size and be used in the production of new pavements or under the main layer of road as the base or roofing purposes. “Asphalt shingles consist of felt saturated with asphalt, and with mineral stabilizers and rock granules added. Asphalt constitutes 20 to $35 \%$ of the product weight. Contaminants including metal items and any wood waste must be removed" (Laquatra \& Pierce, 2002).

\section{Other Materials}

There are several other materials, which are normally smaller in volume in comparison with other waste materials. Examples of these materials are some types of non-ferrous materials such as copper or stainless steel, appliances, land-clearing debris, electronics, tires and fixtures for plumbing. These materials can have value if there exist a secondary market. Besides, some of the materials of this type require specific handling and management process to go through. Tires for instance must be cut into shreds in order to prevent them from landfill disposal. Some appliances must be handled carefully as they may contain materials, which are related to the hazardous materials category.

\subsubsection{Facility Design}

Normally, in all countries, the principal contractor is responsible for introducing waste disposal methods and performs sufficient supervision to carry out the process efficiently and with acceptable quality. Furthermore, it is indispensable that the design team including architectural, civil and mechanical engineers, contribute to the plan. The plan becomes quite efficient considering the aforesaid contribution and proper supervision (Environment and Energy, 2008). 
There are various ways that engineers can contribute to the construction waste management plan. One of them is trying to use one single construction material to accomplish more than one actions. Actually, the aforesaid contribution must be regarded at the design stage in the material selection process not only from architectural point of view, but also in the engineering part from building structure design to mechanical engineering phase (Napier, 2012).

Another possible contribution is trying to perform an efficient design in terms of dimensions of different building elements, in order to minimize the area and volume of different parts. Less material is equated to less waste material. Dimensions of products as well as their standard by which they were produced must be monitored carefully, as it contributes to the reduction of cutting and fitting needed for every single product which would lead to the generation of less construction waste materials (Laquatra \& Pierce, 2002).

It should be noted that the method of implication of a residential building project is directly related to the amount of waste that is going to be generated. In some construction methods, temporary construction support, in order to prevent the structure from collapsing is indispensable. The usage of these materials would lead to an increase in construction waste generated (Napier, 2012).

Another contribution is to select materials that do not need adhesives for application. In this case there would be less cardboard waste and less need for containers to carry adhesive materials. Besides, the usage of adhesives contributed to less valuable waste materials at the demolition phase as more construction waste in contaminated with 
waste and the picking, sorting and recycling processes would be more costly, as materials may end up in landfills (Napier, 2012).

The usage of materials, which are sensitive to damage, must be minimized during the design stage. It should be similar with materials, which require considerable environmental provisions or sensitive to contamination. This would reduce the onsite waste to a great extent. Besides it is recommended that the designer should try to "reduce requirements for applied finishes, laminates, coatings, adhesives, and the associated scrap, packaging, and waste, and select materials with integral finishes" (Napier, 2012).

In this chapter, construction waste management as a process is introduced. The process is demonstrated as step by step and the materials, which are normally the result of a construction or demolition action, were mentioned. Besides, the value of each material is highlighted.

In addition, criteria and consideration for designing waste recycling facilities were highlighted with regard to the priority of actions which contribute to performing waste management more efficiently and it was concluded that the separation process is the most important phase, efficiently performing which would make the rest of the stages of actions easier to be performed and it would also increase the efficiency of further steps financially.

In any new research and development topic, there are leaders who have the most proper situation and team to be the pioneers of such projects. C\&DW is not an exception; and therefore this study will take three countries, which have leading roles in generating and developing the C\&DW. 


\subsection{Stages of Construction Waste Management}

Researches, which focus on the criteria of construction waste management, are classified in specific stages; starting from the design level until the phase of demolishing buildings. The priority that drew attentions to create plans for such purposes has been involved with environmental and economic impacts of the building sector on the society. For instance, different countries run surveys and researches within vast criteria in the field of waste management at different levels; while the results are giving a picture of their present situation in this field and also same results are to be used for organizing management plans.

According to (Jong, 1998), the easiest way for a designer to get involved with sustainable design is to select environmentally sustainable materials in their design. Taking the life cycle design into consideration, there will be important guidelines in order to choose building materials. Accordingly, a material's life cycle is divided in three phases: pre-building, building and post-building. The diagram below shows three phases of material life cycle in brief.

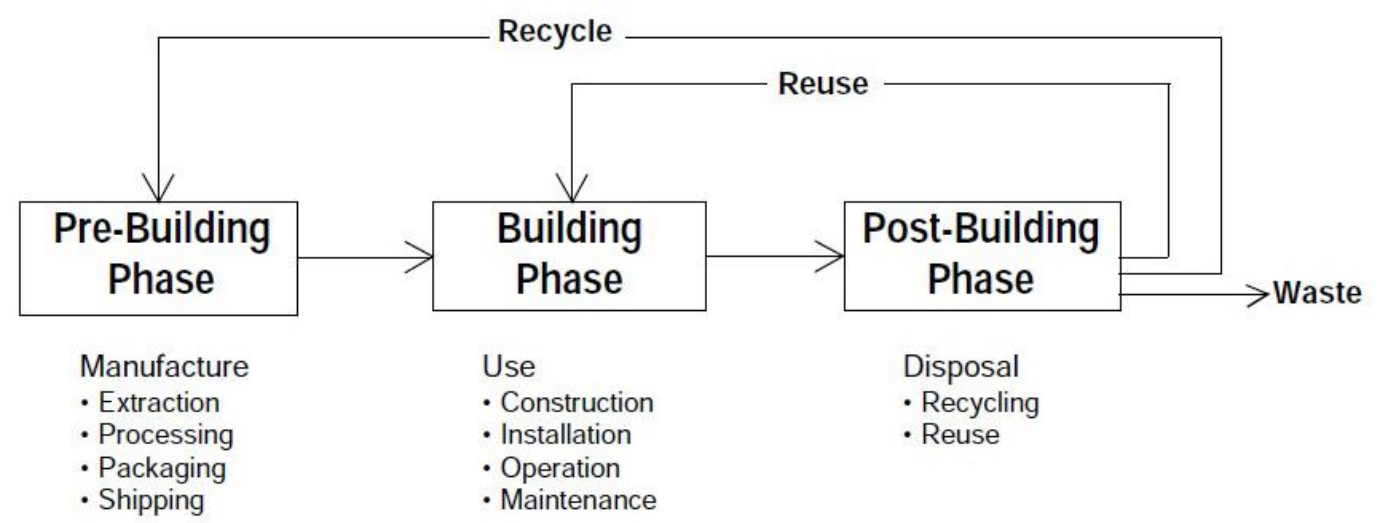

Figure1. Building Life cycle Phases. 
According to OECD report in 2003, three specific targets are mentioned in C\&DW in general. Policy instruments are designed in three stages related to the life cycle of buildings for the purpose of minimizing the C\&DW. Regarding to this study the three stages are:

1. Upstream stages: the stage of design and construction, regarding to improve characteristics of the building related with waste generation such as recyclability or reusability.

2. Demolition stages: disposal wastes generated by demolition of buildings.

3. Downstream stages: recycling and reusing the waste material after demolition.

As it has been mentioned before, researchers preform studies among these stages to find out solutions and methods for improvement of CWM in various countries. In order to have better understanding of the nature of this type of research there are examples worthy to be mentioned.

\subsubsection{Researchers Surveys Samples}

There have been researches took place in different stages of C\&DW, or even overall researches to find out pros and cons, benefits and week points in performance of C\&DW in different countries and various construction projects. There are some examples brought in following lines, which were carried out in different stages. 


\section{Upstream stages:}

Eramla (2009), evaluated the construction and demolition waste management in Hong Kong, and highlighted the shortcomings of the current industry by assessing the willingness of industrial participant to contribute to different waste management strategies.

The importance of reducing waste materials by designing the waste out at the design stage by the architect of a project is highlighted by (Osmani\& Glass \& Price, 2008). They used United Kingdom as case study in which 91 million tons of C\&D waste is estimated in 2003. The responsibilities and obstacles for architects in United Kingdom toward waste minimization, the origin of generated construction waste material and design practices towards the reduction of waste in UK is evaluated using questionnaires. They figured out that carefully designing a building by considering both construction, operation and demolition phases before the initiation of construction and taking them into account by architects can reduce waste generation to a great deal.

They concluded that despite the fact that more that $30 \%$ of waste is generated as the design stage, waste minimization at the architectural design stage is not a priority for architects and they are unaware of the fact that a considerable share of waste is attributed to their design, and the majority of waste is generated on the construction site as the result of defective implementation (Osmani\& Glass \& Price, 2008).

\section{Demolition stages:}

Osman bin (2009) evaluated the situation of construction waste management in Singapore, and concluded that although more than $85 \%$ of construction and demolition waste is recycled in Australia, the situation should be improved by trying 
to reuse more of the waste like incinerator bottom ash for road works. The significant factor is governmental contribution as established by Osman bin (2003).

\section{Downstream Stages:}

It was reported by (Al-Mutairi, Kartam, Al-Ghusain, \& Al-Humoud, 2004) that despite efforts to minimize the waste, which is being disposed in landfills in Kuwait, the management of C\&D waste has not been successful in Kuwait, especially in terms of environmental effect and drawbacks as the result of landfilling. They presented the requirements for recycling waste from construction and demolition in Kuwait, potential use as well as the limitations for the case of recycling waste materials and possible solutions to reduce the amount of construction waste in Kuwait. Furthermore, they carried out an investigation of the available market for the waste material, which are recycled in order to assess the feasibility of implementing a new recycling service.

Besides, waste material in Kuwait that are being landfilled is quantified by the authors. The potential demand, design capacity and marketing strategy of construction a recycling plans in the case study of Kuwait with the aim to reduce the landfilled waste and promote the recycling technology and culture in the industry is also evaluated.

(Wang \&Touran\&Christof\&Fadlalla, 2004) Carried out an investigation on the economic impact of a solution toward encouraging the recycling and reusing solutions, which is restricting landfill disposal for C\&D waste material if they are not processed to for reusing or recycling purposes. They carried out their investigation 
by developing spread sheets based on mass principle in order to compare different scenarios in managing the waste by implementing the aforesaid method.

(Wang\&Touran\&Christof\&Fadlalla, 2004) used the city of Massachusetts as their case study. The stream of waste in different stages of recycling, generation, separation at the source and disposal was tracked by this method and by employing a comparative analysis for the collected data, costs and benefits associated with each stage, scenarios were compared.

They concluded that if the efficiency of labor is increased to one ton per man-hour, separation cost in total will decrease to $25 \%$. It was suggested that although the cost of waste disposal is affected by the market, contractor's efficiency could be improved by training and planning.

It was argued by (Nunes\& Mahler \& Valle \&Neves, 2007) that very few recycling centers are available for construction waste materials in Brazil. The possibility of the generation of new recycling unit is investigated by using a conceptual model. It was established by authors that it would be impossible to finance the operating and maintenance cost of a new recycling unit in Brazil, and recover investment costs as well, by relying only on the revenues which are forecasted in the feasibility study, as the result of selling recycled waste materials. The reason behind this matter was that the usage of recycled materials in not popular in the case of Brazil.

However, it was reported that if the unit continues the operation at the desired capacity and volume, it is feasible for public authorities to build and operate the 
recycling unit. Besides, it was concluded that it would be profitable to invest in this industry not only for public sector, but also for private sector in developing countries.

(Mulder\& de Jong \&Feenstra, 2007) Proposed a new concept in reusing C\&D waste materials in Netherlands, where they declared that the reusing process is carried out efficiently and to a noticeable extent -almost $95 \%$ of waste is reused for road construction purposes - already. They suggest that quality of the materialsthat are going to be reused is maximized while quality of the waste material that are going to be disposed is minimized.

For waste masonry materials or waste concrete which includes clay bricks, concrete particles in different sizes, sand and gravel), it is suggested that they are fully recovered in a complete cycle by having them get through thermal processes. In addition, they are separated and their contamination is eliminated by using special dry separation procedures. As the result, as the quality of processed waste material is improved, they can be used in concrete as fresh aggregates, instead of road construction (Mulder, de Jong \&Feenstra, 2007). They also highlighted the importance of their investigation in terms of the reduction in the consumption of energy and emission of carbon dioxide and the reduction in the usage of land for landfill purposes. The proposed thermal process to improve the quality of materials is carried out by using a part of waste materials and there would be no need to consume additional materials for energy generation. Additionally, the proposal reported to be economically similar to the existing method.

There are some researches that are carried out with an overall look on all three stages to get major results such as the ones that are mentioned below: 
Dezs (2005) developed a waste management plan for his case study, which was Hajdú-Bihar County by assisting the competent authorities in their future tasks; it has been on the existing situation of waste management in Hungary, by taking the economic and financial factors into account.

Using a qualitative method, questionnaires and interviews, it was concluded by (Tam, 2008) that the proposition of new solutions to reuse C\&D waste materials on the construction site, reduction of waste on-site, and an increase in the productivity of constriction companies are the advantageous results of promoting the waste management plan which has commenced in Hong Kong construction industry since 2003.

Yet it is not completely possible to separate all three stages clearly to come to conclusions for each stage of C\&DW. According to the given information above and also to the mentioned examples from previous researches, there are some issues to consider. For waste reduction purposes, it should be noted that if materials, which are going to be used in the construction are ordered before, and the amount and size of them are well calculated before, the amount of waste could be decreased to a great extent (Figure 1). 


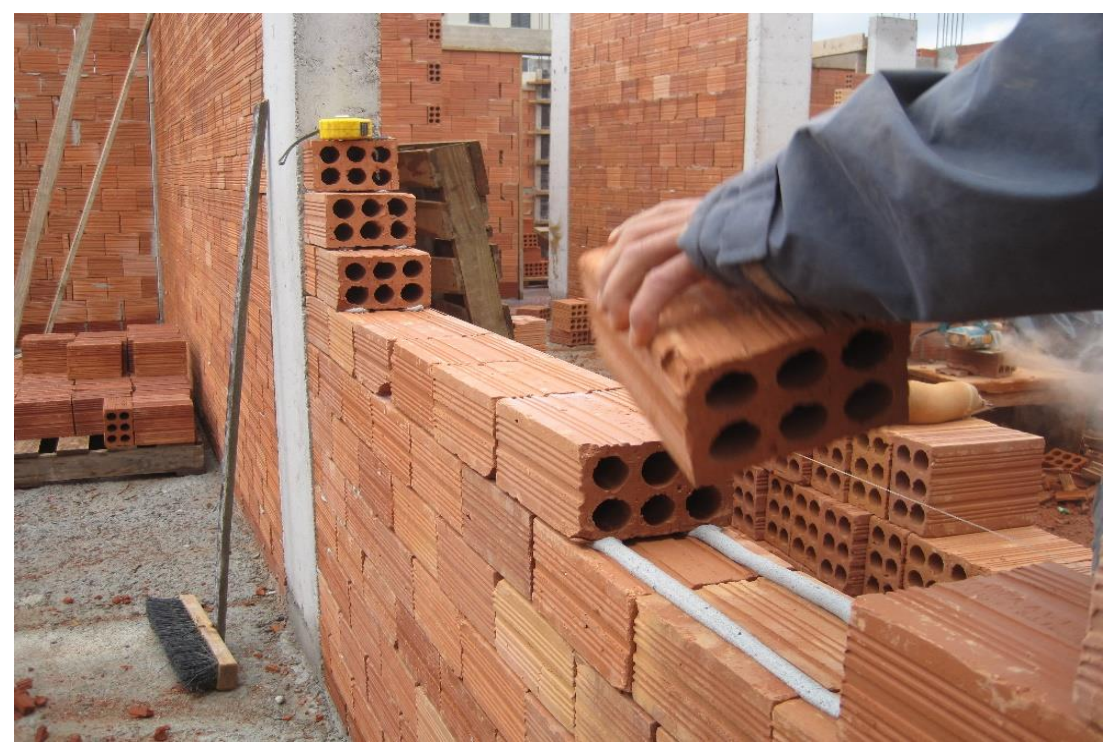

Figure 2. Avoid excessive ordering

Besides if construction includes deconstruction for example, old materials can be sorted out and be reused in the new construction to avoid material waste and excessive material ordering (Figure 2).

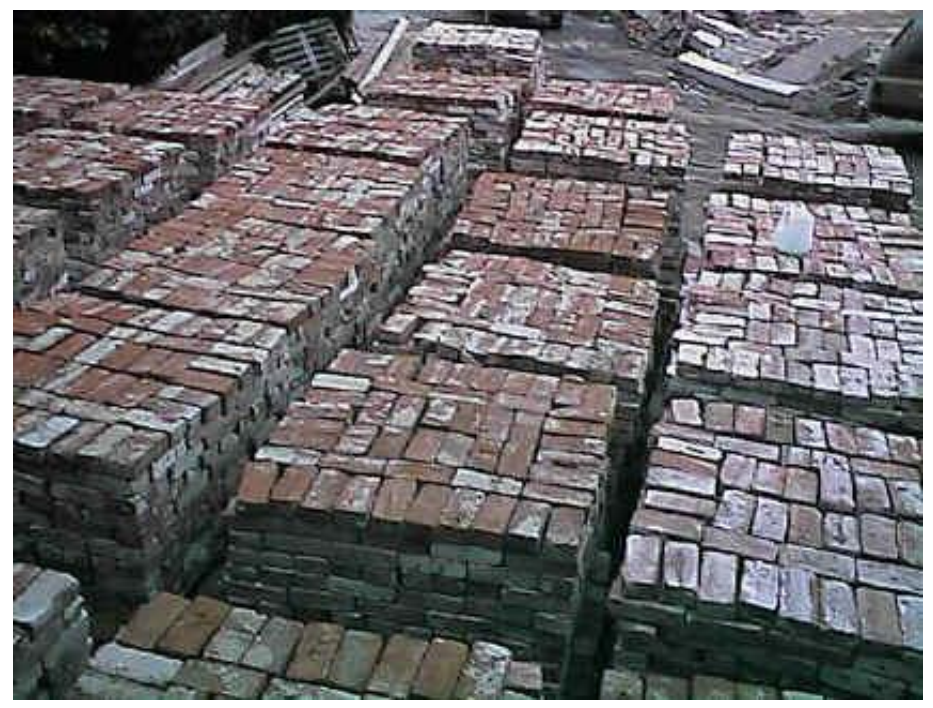

Figure 3. Reusing old materials 
On the other hand, by carefully packing and handling materials, on-site waste generation could be decrease to a considerable extent (Figure 3).

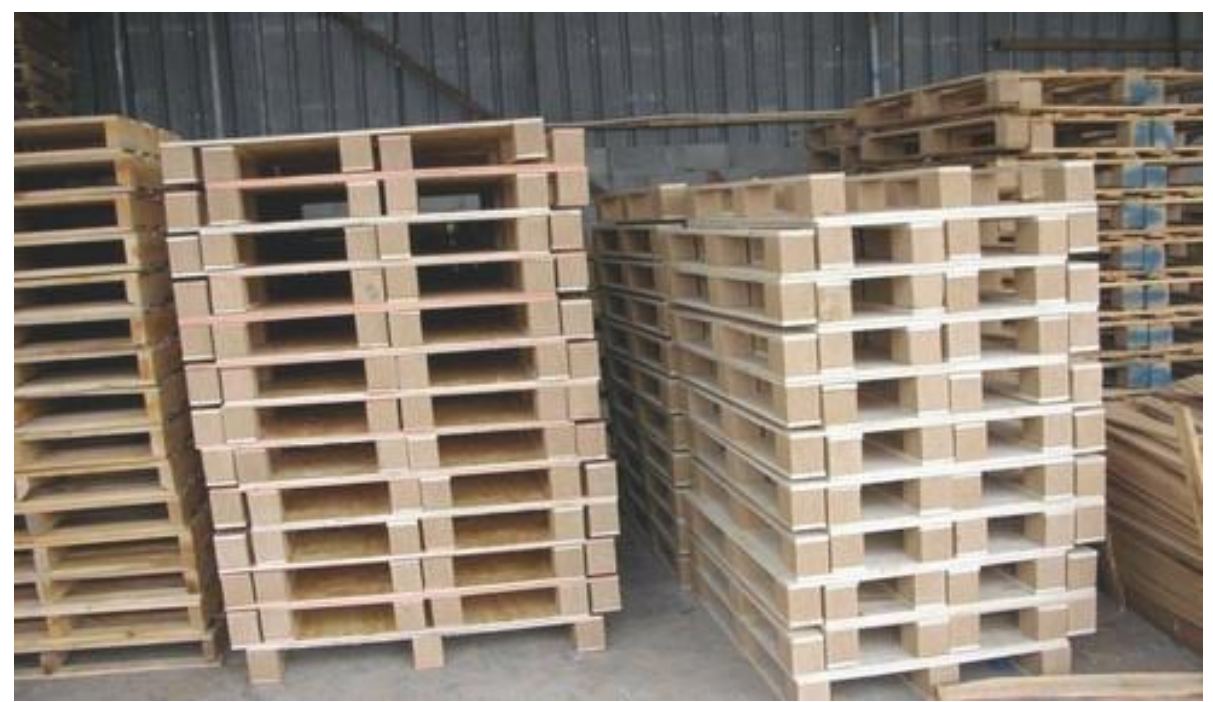

Figure 4. Packing and handling minimizes on site waste

Some impediments in the implementation of this plan were also reported including comparative additional costs which are attributed to the promotion of this scheme, as well as the increase in overhead costs. The aforesaid reasons prevented contactors and companies to be eager to apply the plan in their projects. Prefabricated elements for construction industry are considered as the proper measure to reduce the amount of generated waste in construction and demolition industry in Hong Kong, as their comparative additional cost is smaller than employing waste management plan in each and every project (Tam, 2008).

This type of research not only estimates the amounts of waste material on construction sites or other effects of CWM, they also expose the fact that construction waste management has its own effects on the economy of the projects; both in the time of construction and after finalizing projects. For 
instance,Kofoworola\&Gheewala, (2009) have worked on the construction industry in Thailand. They reported that almost $8 \%$ of total waste, which is disposed in landfills or dumpsites are attributed to construction and demolition sector from 2002-2005. It was stated that in recent years, waste recycling is promoted and absorbed several attentions as the result of excessive disposition of waste in undesignated fields. It was estimated that as many as 4000 job opportunities could have created in that specific period by employing recycling measures for construction waste. In addition, a noticeable amount of energy would have been saved as the result of construction waste recycling. If adequate information is collected regarding the available waste materials for recycling purposes, it would contribute to feasibility study of constructing more recycling centers in Thailand to a great extent (Kofoworola\&Gheewala, 2009).

As a matter of fact, it is almost impossible to exclude any of the three stages of life cycle while running a construction project from zero level to the maintenance even after finalizing the construction. In this respect there are examples that bring the whole three stages as a chained issue in the field of CWM; as SolísGuzmán\& Marrero\& MontesDelgado \&RamírezdeArellano (2009) declared, the resect regulation for the management and production of $C \& D$ waste materials in Spain. The quantification of the volume of waste material that is going to be produced is required to be carried out by contractors and construction companies. Besides, their waste management plan for the estimated waste must also be presented. The model for managing waste which was the inspiring element of the national decree of Spain to regulate the implementation of waste management plan in presented in their work, and a comprehensive model with adequate details is provided to be used for waste 
volume estimation. The model is stated to be the result of an analytical study of more than 100 residential projects using the bill of quantity of each project, their wreckage, packaging and demolished volume. Two caste studies were also presented to justify the presented model for estimation (SolísGuzmán\& Marrero\& MontesDelgado \&RamírezdeArellano, 2009).

In terms of material use, there is also concern when it comes to estimation of waste material in construction sites. In fact the amount of waste generated from different materials is different according to the type of used materials. For example, ( $\mathrm{Lu}$, et al., 2011) analyzed the waste generation rate in South China, by sorting and examining waste material in four different construction projects and concluded that the majority of waste materials were timber from formwork, concrete, and timber from false work.

The main reasons behind waste generation in the construction industry of China was also examined by (Lu , et al., 2011) and as the result they proposed that a reward program should be considered to encourage waste management program in China. Besides, they suggested replacing current timber framework system with metal framework system to reduce the waste timber on the construction site. Carrying out the sorting of waste material at the source and replacing professional workers for these specific tasks of uploading, sorting and managing waste material would contribute to the reduction of waste disposals to a considerable extent.

In this part of the study, concepts and procedures of waste management in the construction and demolition industry, in residential sector is accounted for and 
explained. Besides, leading countries in the aforesaid management activities were introduces, and their contribution to the science and implementation of management measures were accounted for. At last, the contributions of other scholars taking different case studies all around the world is demonstrated and important findings and results of their study is highlighted.

It was mentioned that the management of $C \& D$ waste materials is performed more seriously and comprehensively in developed countries and the reason behind it is that the technology to recycle materials is available in developed countries to a greater extent in comparison with developing countries and there is no need to spend too much financial resources for these countries to transport or export waste materials to be recycled.

Besides, in developing countries, normally there is more space available to be used as landfills and there isn't any concern about the shortage of landfills while in developed countries, the availability of landfill is a very important and growing concern, and a very strong motivation for the application of waste management plans.

It was also established that the foremost measure to be taken in the procedure of waste management is trying to minimize waste materials even from the architectural design stage, so there is no need to spend resources to manage, reuse or recycle waste materials. 
Furthermore, it was realized that regulating waste management as well as carrying out the sorting activity of waste material on the construction site reduces the following costs for reusing and recycling materials to a great extent.

For this study is done due to examine potentials of C\&DW in North Cyprus, it is also worthy to mention that there has been several works published on different problematic aspects of the construction industry of Northern Cyprus but the focus on waste management has been limited to energy waste minimization by Mohamadi (2012) and Mohamadi and Mirnoori (2012) who performed an analytical investigation of minimizing energy waste in residential buildings of Northern Cyprus.

With all aforementioned data and regulations in terms of C\&DW management, there is a necessity to explain the construction process in a more comprehensive manner in order to have better understanding and also to be aware of the specific factors that are to be considered in case of CWM.

\subsection{Construction Process}

According to what a construction project takes to be finalized, there should be ways of managing the waste material in order to create management plans. There are five most important steps that need to be considered in the process of waste management.

The first step is elimination: In this step, it should be regarded that not generating waste is the most efficient way for managing waste. This could be achieved at the design stage and in the construction stage by educating workforce. 
The second step is to reduce the amount of waste that is produced as the result of a construction project. This step is directly under-influence of proper site management as well as higher degree of education for the workforce.

The next step is to re-use the inevitably generated waste at the site. This step is extremely crucial as waste reduction at this stage is cost-effective. The reason behind is that there is no need for transportation and there is no need for extra technology as well.

The fourth step is recycling, which is directly related to the available technology, and possibilities to which waste materials could be transported and delivered.

The final stage is disposal, which is not desired as the purpose of the whole waste management process is the minimization of this last stage. By the way, in several cases, disposal is inevitable and requires its own considerations to be performed efficiently (figure 5). 


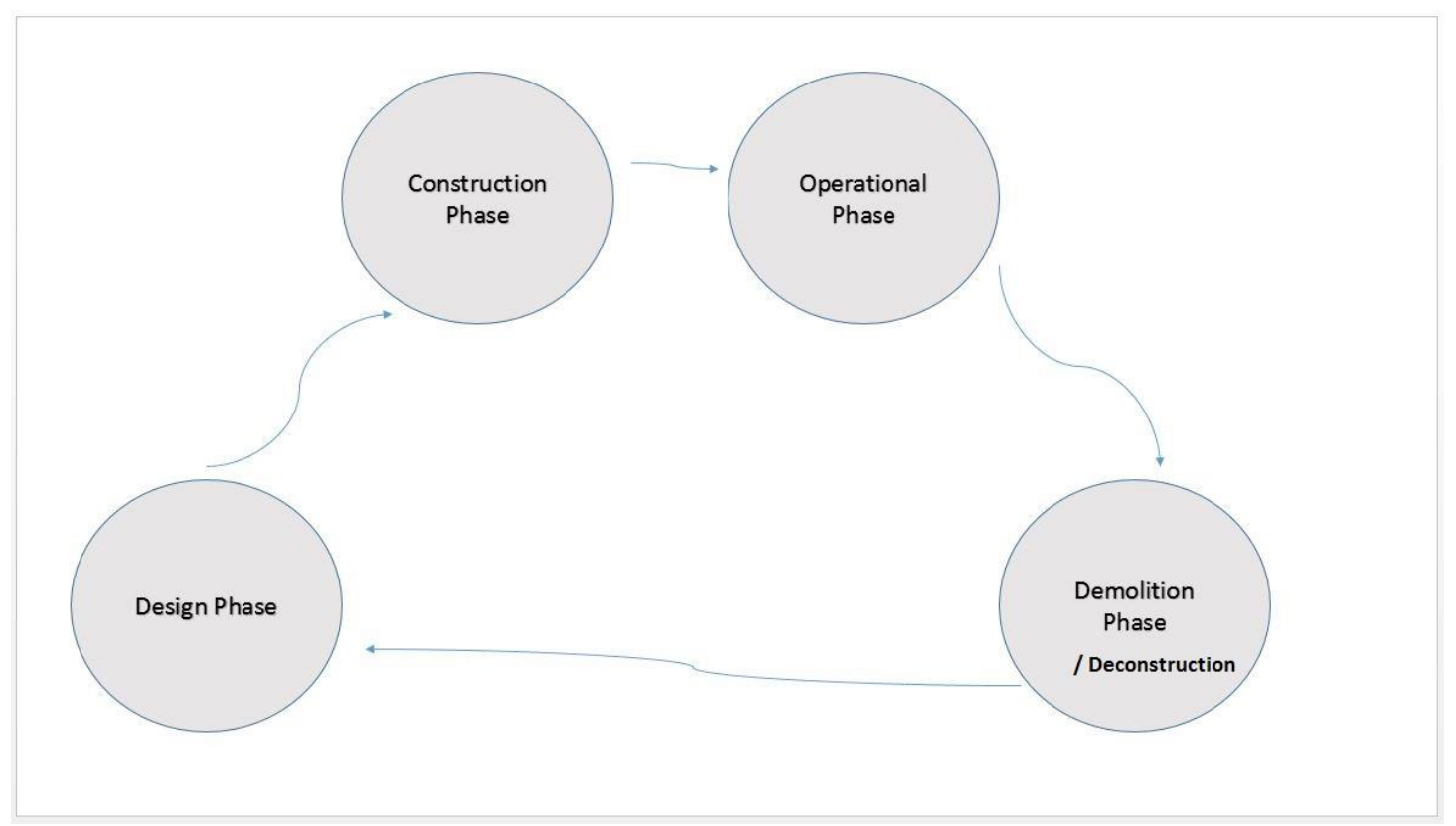

Figure 5. Waste hierarchy

According to the waste hierarchy, which has been presented, there are details to be considered in the process of construction waste management as below:

1- Investigate on the possibility of reducing packaging in ordering materials.

2- Encourage designers to design according to market availability in terms of availability and type of presentations and packaging.

3- Pre order materials to specifications at the design stage to reduce waste from modifying materials.

4- Avoid over ordering to save money, as it will increase waste materials.

5- Investigate on the package return possibility.

6- Realize the possibility and the quality of waste return to material suppliers.

7- Use the excavation waste material in site preparation.

8- Develop a training program for all workers so they are familiarized with waste management plan and disambiguated in order to be able to cope with the plan and work efficiently. 
9- Estimate how much materials will be delivered to the project at every defined time-span and try to estimate the waste material which is going to be produced.

10- After estimation, it is possible to decide about reusing, recycling and disposing materials with respect to the available technology and possibilities.

11- Take into account considerations for hazardous waste if it could be any.

12- Provide different containers on the site for each different type of waste not to mix waste materials together which will end up as disposals.

13- Design waste management plan and make sure everyone has access to it on the construction site.

14- Keep track of waste disposal as they need to be disposed legally.

15- Monitor staff carefully.

16- Update waste management plan regularly.

17- Prepare site waste management checklist.

By mentioning abovementioned details, from the stages before the starting point of a construction project, by considering different aspects of waste management, construction waste management is proceeded in order to meet the necessities of a sustainable design and construction project.

\subsection{Leading Countries}

Although in most of the countries, specially developed societies, construction waste management is implemented at different scales and levels, there are some countries in which the management of $C \& D$ waste materials is carried out more systematically and under the specific rules of government, state or municipality. Hence, overtime they developed frameworks for their management applications. 


\subsubsection{England}

The Site Waste Management Plans Regulations came into force on 6 April 2008 and require any person intending to carry out a construction project in England with an estimated cost greater than $£ 300,000$ to prepare a site waste management plan (Hayward, 27). The estimated cost although is the figure excluding VAT. Besides, as the plan must be prepared prior to the construction commence, if project is initiated prior to the preparation of the plan, not only the principal contractor, but also the client will be fined.

The government of United Kingdom reported that in this regulation, construction site is defined as any location within which a construction activity is carried out, or to any location that workers have access to. Besides, the construction work must be described in detail, in term of the estimated cost and the location of the construction site. Additionally, the quantity and type of waste materials which is forecasted to be produced during the project should be described. For each material, there must be an action proposed for managing the waste that is going to be produced from that specific material, in order to reuse, recycle, or reduce (UKGOV, 2008).

A declaration should be included in the documents of the plan, in which client as well as the main contractor is responsible for efficient handling and proper managing of waste materials. They must also ensure that "all waste from the site is dealt with in accordance with the waste duty of care in section 34 of the Environmental Protection Act 1990 and the Environmental Protection (Duty of Care) Regulations 1991" (UKGOV, 2008). 
It is regulated that after waste materials are removed from the construction site, in case of the cost of the project is 500000 British Pounds or less it should be recorded by the main contractor the information about the process including the identity of the company and the person who eliminated the waste as well as types of materials which were removed from the construction site and the destination to which waste materials were taken to. It should also be noted that within 3 months after the project is terminated, the main contractor must provide additional information about the waste management process, including regular confirmation of the plan being monitored and carried out according to the regulations and plan schedule, and any deviation from the main waste management plan must be accounted for (Hayward, 27).

In case of the cost of the project is greater than 500000 British Pounds, a different approach should be followed. It should be noted that an update for the plan is ensure as soon as waste material is removed from the site. The information should include the identity and information about the person who eliminated the waste, the registration number of the carrier by means of which waste materials were removed from the site, the information of the site to which materials were transferred whether or not the operator was needed to provide a permit under the environmental permitting regulation 2007 or not, and "a copy of, or reference to, the written description of the waste required by section 34 of the Environmental Protection Act 1990” (UKGOV, 2008).

In addition, for the case of estimated cost more than 500000 Pounds, under any circumstances, within every six months, the main contractor must re-evaluate the 
plan, document the types of materials produced as waste and their quantities, the type of materials which were recycled or reused whether or not they were on the construction site and their quantities, types and quantities of on or off-site materials which were transported to another form of recovery or was transported to landfill or disposed. In addition to these periodical updates, the principal contractor needs to provide some specific documents within 3 months after the project is accomplished such as monitoring confirmation, which indicates that the plan is carried out according to the schedule and specification of the originally planned process, comparisons of different materials and their quantities in the planning phase and in the actual project implementation phase, an approximation of savings in terms of money and time, by performing waste management plan, and explanation for any deviation or shortcomings with detailed information (UKGOV, 2008).

It is regulated that the main contractor makes sure that the plan is retained on the site or in case of availability of an office on the site, in the office, and makes sure that every contractor of the project is informed about the place of the plan and required information to reach the plan. The plan must be retained by the principal contractor on the site of the project or at main contractor's main business place for two consecutive years after the project is accomplished.

"To knowingly or recklessly make false or misleading statements in the SWMP is an offence and the party/parties responsible for drafting a knowingly false or misleading SWMP will be liable to conviction" (Hayward, 27). 


\subsubsection{Australia}

A total of 19.0 million tons of construction and demolition (C\&D) waste was generated in Australia in 2008-09. Of this total waste stream, 8.5 million tons was disposed to landfill while 10.5 million tons, or 55\%, was recovered and recycled (Hynder Consulting, 2011).

The government of Australia does not pass laws and regulations directly for construction and demolition management. Actually, every state and territory of Australia is responsible for its own environmental issues (Edge Environment Pty Ltd, 2011).

According to the construction and demolition status report by the government of Australia, the department of sustainability and environment, the resource recovery performance depends on diverse factors related to each state or territory. In each jurisdiction, there are several different driving and impeding factors, which could reach more than 75 percent of recovery rate for construction materials in the best performing territory (Hyder Consulting Pty Ltd, 2011).

In May 2006, the Australian Procurement and Construction Council (APCC) established a working group to develop an Australian and New Zealand Government Framework for Sustainable Procurement (the Framework)(Hyder Consulting Pty Ltd, 2011). The aim of this framework was to provide a guideline for states of Australia as well as New Zealand to encourage the application of the principles of sustainability in the construction and demolition industry. 
It was suggested that the demand for construction materials should be managed, and action-plans should be followed to eliminate dispensable consumption. Besides, the selection of materials with comparatively minimal or lower environmental impacts during their life-cycle was encourages. Furthermore, a viable market for Australia and New Zealand was suggested to be fostered in term of sustainable product and services, by supporting industries that follow sustainability and demonstrate eagerness and innovation in sustainable marketing, products and services (Hyder Consulting Pty Ltd, 2011).

The association of Australian and New Zealand road transport and traffic authorities, released the "Guide to pavement technology part 4E: Recycled Materials" in 2009 and described the characteristics of recycled pavements which are produced from waste materials. Waste materials which were profiled in the guideline, were not only from construction or demolition activities. Besides, for the materials to be accepted for pavement manufacturing, they should be trough registered waste processing facilities. However, specifications and application of specific waste materials from construction and demolition sector is also profiled in the guideline (Porter, Andrews, \&Rebbechi, 2009).

A summary of construction and demolition related legislation is presented in Appendix B.

\subsubsection{Canada}

Traditionally, the process of handling waste material as the result of construction, renovation or demolition of buildings is a lost opportunity. Most of the materials that are being thrown away, are valuable items, as they can be reused or recycles for 
further construction purposes. Additionally, "as the cost of construction materials escalates due to dwindling virgin resource availability (especially lumber), many of the materials that we throw away are becoming increasingly valuable" (PWGSC, 2012).

The most important part of the process is the separation of this type of waste from other materials as they are items of value until contaminated and mixed with when they lose their value for reusing and recycling purposes at the same cost.

In most cases and most countries, a noticeable share of total waste generated annually, is attributed to the construction industry. For instance, in Canada, almost a quarter of solid waste, in the category of non-hazardous, comes from construction or demolition fields. In the case of Canada, jurisdictions are focused on keeping the waste from construction industry as far from landfills as possible as the whole process consumes considerable resources of values, affects the environment and increases the demand for additional landfills. It was reported that it is more difficult to find proper landfill locations as time goes by, as more people are opposed to the existence of landfills in their neighborhood (PWGSC, 2012).

In 2009, Canada wide-action plan for extended producer responsibility is approved by CCME, which is the Canadian council of ministers of the environment. The extended producer responsibility is introduced by this action plan, and difference provinces and territories are obliged to follow the introduced obligations by 20152018 for construction and demolition wastes. On the other hand, Canadian home builders' association supported all activities toward environmental friendly housing 
practices and the development of such actions since mid-80. The focal point of these activities was to reduce the amount of generated waste during construction or demolition activities, to use recyclable materials in residential construction, to reuse waste materials during construction phase, and to build more durable buildings in order to reduce the demand for construction materials and products (CHBA, 2010).

In addition, CHBA believes in DE measure, which is a method to reduce the amount of waste at the design stage, as well as optimum value design and engineering that helps designers and engineers to decrease the amount of input material which consequently leads to a reduction in waste materials as well. In term of reuse, CHBA believes that it is more applicable in residential sector at renovation level; however, the association suggests that building codes must be addressed as they may be opposed to reuse activities. The most significant approach to waste reduction is attributed to recycling as believed by CHBA, and they highlight the important role of private sector for the process being as cost effective as possible. Besides, the option of reclamation and conversion should be considered for waste materials which could not be managed by applying recycling reusing or reducing methods (CHBA, 2010).

From the point of view of costs and additional extra expenditures for waste management, it is suggested by CHBA (2010) that "The incremental costs of new construction waste management systems should be borne in proportion to the use of such systems. Builders who generate less waste per unit output should pay less".

There have been several regulations issued to prevent illegal dumping construction waste in landfills and to reduce the amount which is transferred to landfills legally. 
There regulations are to be taken into action prior to any disposing or handling activities.

\subsubsection{Ontario's 3Rs Regulations}

The 3Rs regulation was passed in 1994 by the ministry of environment in Ontario. Regulations 102/94 and 103/94 are applicable to construction and demolition projects consisting of one or more buildings with a floor area greater than $2,000 \mathrm{~m}^{2}$ (PWGSC, 2012). Regulation 102/94 suggests that a work-plan must be developed for decreasing waste purposes and each options and detailed information for reuse, recycle or waste reduction should be addressed as suggested by PWGSC. It was also suggested that the aforesaid work-plan should be implemented. Work-plan results must be documented on forms, which are provided by the ministry of the environment or those which created with the same format. Finally, forms are retained after the accomplishment of the project for a period of five years.

On the other hand, 103/94 regulation follows the characteristics of the machinery and facilities which are being used during the waste management process in activities such as handling and collection. In addition, it requires that adequate effort is invested on reusing or recycling the waste (PWGSC, 2012).

Considering the municipality, types of materials which could be disposed so each landfill and specific attributed regulations that are enforced, should be studies prior to each construction or demolition activity. Besides, contracts must be ensured to contain only legal and permitted landfills for waste materials to be disposed (PWGSC, 2012). 


\subsubsection{Comparison}

In order to be able to compare the regulations and contributions of leading countries, building codes and state, national, or municipal regulations must be issued with regard to a uniform framework or category of codes, so the implementation process and the degree of productivity of each country could be compared while, each of the aforementioned leading countries in the field developed their method of waste management independently and with regard to their individual issues; however, they could be compared with a rather broad perspective.

For instance, in the United Kingdom, the most important part of implementation and supervision of waste management plan must be carried out by construction manager and their crew members. Actually, it is required that the construction manager of every project to monitor and report the ongoing waste management, which must have been designed for every individual project. Besides, the regulations in United Kingdom are implemented at the national scale while in Canada and especially in Australia; the waste management-related regulations are issued, followed and implemented independently and differently in each individual state.

Additionally, In Canada and Australia, the regulations are required to be reflected in construction contracts and could be diversified to different contractors of the project separately, rather the principal construction manager.

In all three countries, it is regulated that a waste management plan must be designed and tailored for each individual residential construction project, prior to the initiation of construction phase. 
Table 1. Comparison CWM (Construction Waste Management)

\begin{tabular}{|l|l|l|l|}
\hline Country & United Kingdom & Canada & Australia \\
\hline $\begin{array}{l}\text { Year of } \\
\text { regulation } \\
\text { establishment }\end{array}$ & 2008 & 2009 & 2006 \\
\hline $\begin{array}{l}\text { Responsible } \\
\text { authorizations in } \\
\text { performing } \\
\text { regulation }\end{array}$ & $\begin{array}{l}\text { Construction } \\
\text { manager and their } \\
\text { crew members are } \\
\text { responsible for } \\
\text { monitoring }\end{array}$ & $\begin{array}{l}\text { contracts and } \\
\text { could be } \\
\text { diversified to } \\
\text { different } \\
\text { contractors }\end{array}$ & $\begin{array}{l}\text { coflected in } \\
\text { construction } \\
\text { contracts and } \\
\text { could be } \\
\text { diversified to } \\
\text { different } \\
\text { contractors }\end{array}$ \\
\hline Need for WMP & $\begin{array}{l}\text { reguired to be } \\
\text { projects }\end{array}$ & required & required \\
\hline
\end{tabular}

According to the broad data mentioned in this chapter C\&DW plans need feasibility studies. These studies vary according to different factors. One group of factors refers to the three stages of Building life-cycle; and depending on which stage the project is focusing on, there will be specific research, observation and surveys done. Another group of factors includes the specificity of the place (site) and the regulations of each country where the project is running in. to extent that the present study declares, each and every project has specifications by which especial plan should be organized in order to be able to run C\&DW for it. In this regard, if there are any specific regulations given to the responsible people and firms for architectural projects, the next step will be every single projects contractor, designer and constructor to plan a system to manage the construction waste. 
North Cyprus is not an exception; and since natural resources in this region is very limited, managing waste in design and construction projects will face different challenges. Therefore, there is a potential to propose alternatives for C\&DW management in different stages for construction projects. This way there will be more space for considering sustainable design in the building market and industry. 


\section{Chapter 3}

\section{CWM SITUATION IN TRNC}

\subsection{Introduction to the Northern Cyprus and Famagusta}

\subsubsection{Northern Cyprus}

Cyprus as an island is the third biggest island in Mediterranean region by area. The distance of Cyprus to Turkey is 75 kilometres on the North side of the Island.

From geography point of view, Cyprus is dominated by two significant mountains of Troodos on the Greek side and Kyrenia on the Turkish side (TRNC). Half of the western and southern part of the island is covered by Troodos Mountains. On the other hand, Kyrenia Mountains occupy less area on the Northen side and are not as high as Troodos Mountains (figure 6). 


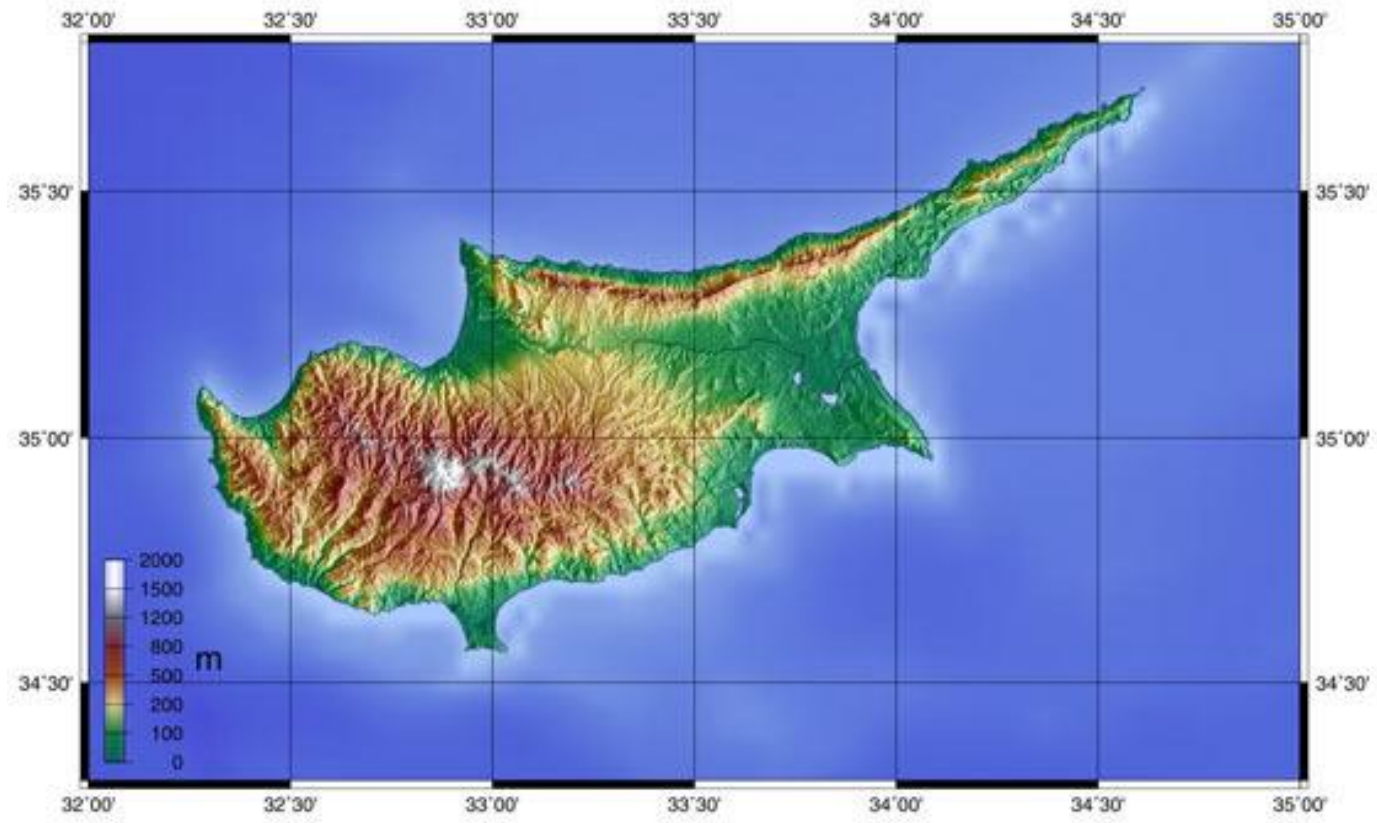

Figure 6. Cyprus Geographical Map

As the result of deforestation, access to year-round supply of water is damaged and is difficult at the moment. Winter wasters flow from Troodos Mountains in every direction, which are controlled for farming by dams. There are all different kinds of vegetation in Cyprus and 17\% of the island is considered as woodland.

\subsubsection{Famagusta}

The city of Famagusta is located on the eastern coast of the country of Cyprus, and Eastern side of the capital of Lefkosa (Figure 7). 


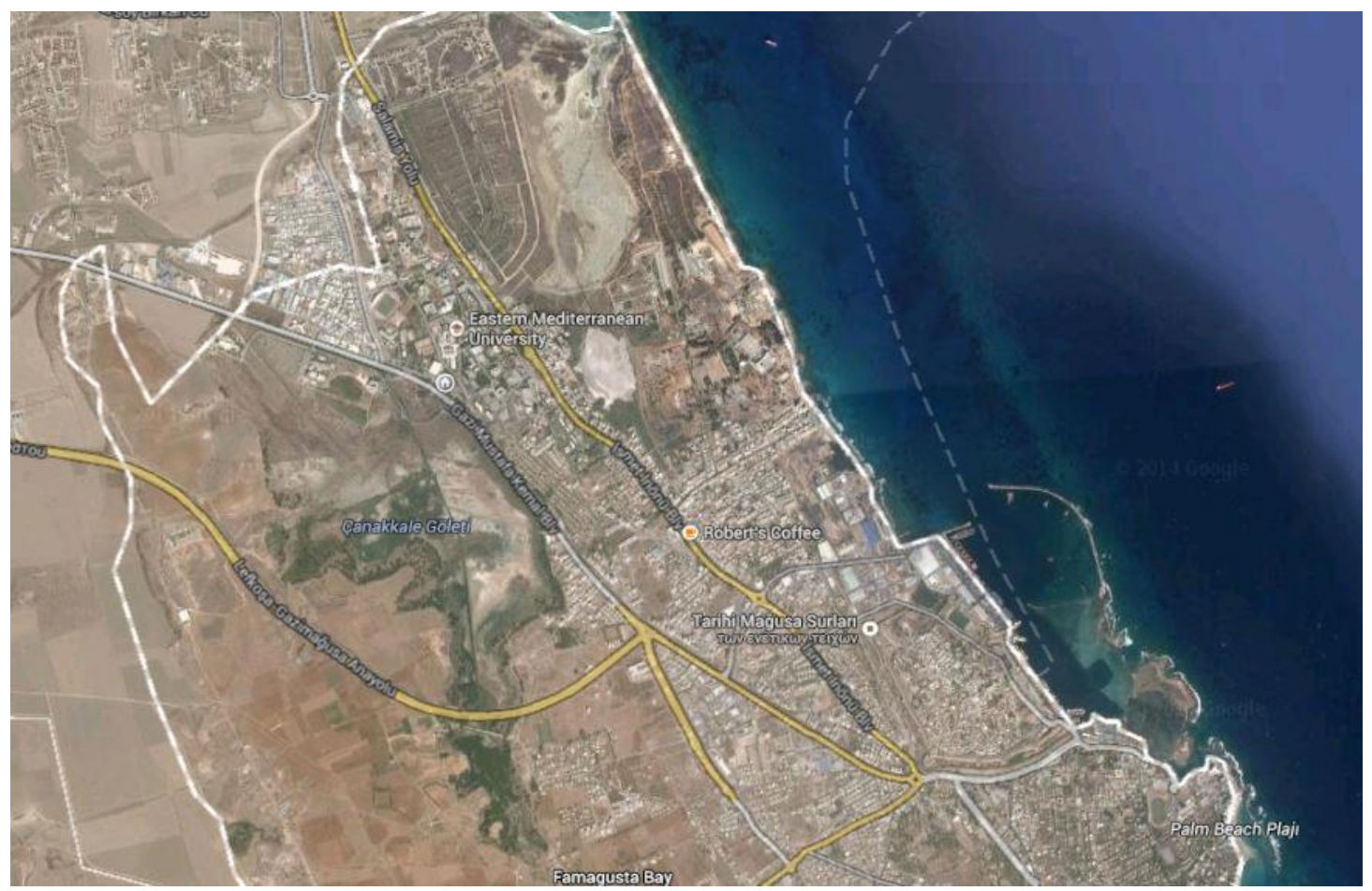

Figure 7. Famagusta

The deepest harbour of Cyprus is also located in Famagusta. The city of Famagusta is one of the most important cities in Northern Cyprus in terms of historical heritage and tourist attraction. However considering using mountains for construction and construction waste disposal, situation of Famagusta in terms of managing construction waste is unsatisfactory.

\subsection{Current Situation of Material and Waste Material in Northern Cyprus}

The required aggregate for concrete production in Northern Cyprus is directly provided from mountains (figure 7). Rocks and stones are collected from mountains and are being used to manufacture concrete and this is a major issue toward the environmental sustainability. 


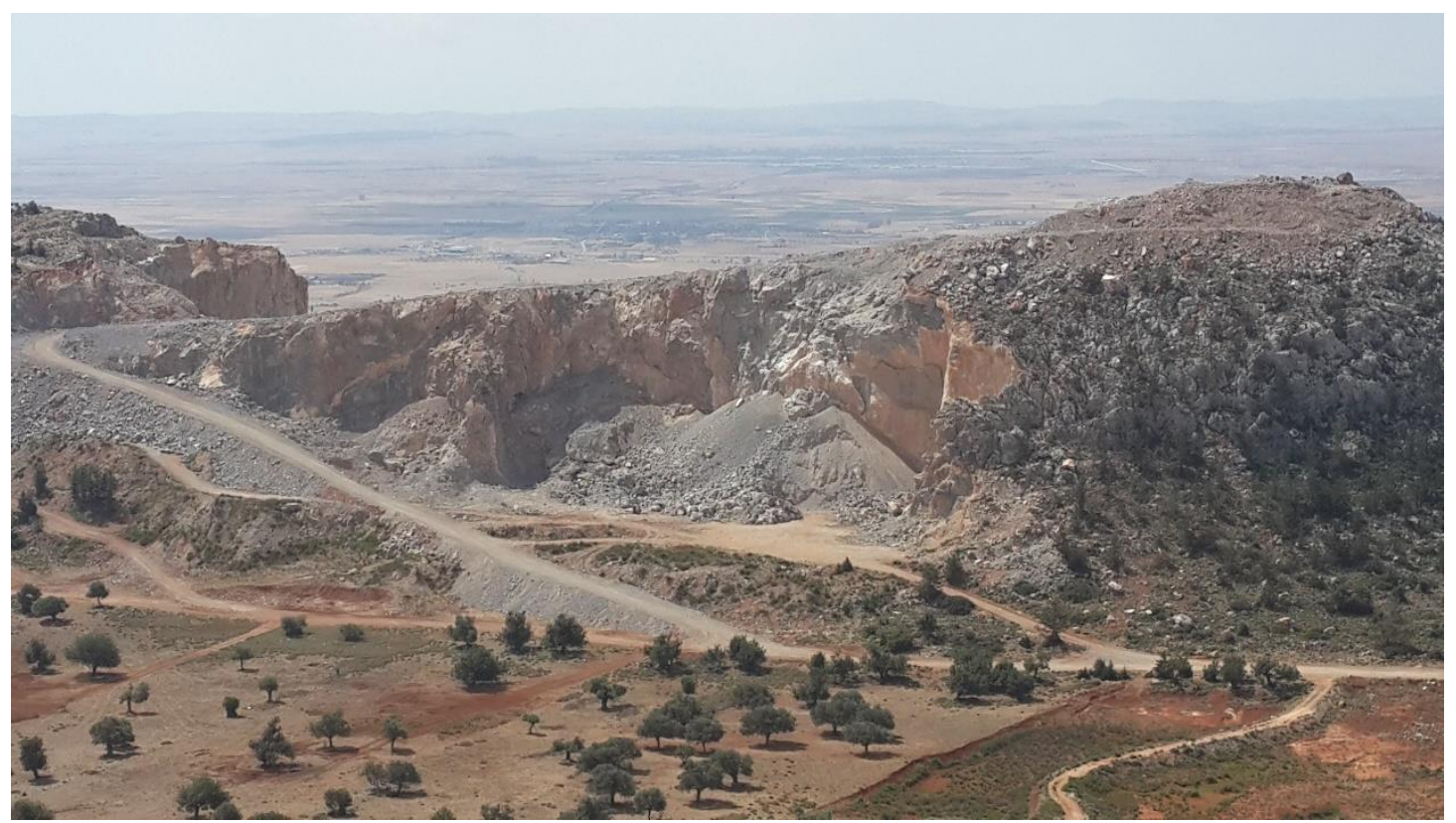

Figure 8. Mountains as sources for aggregates

It should be noted that concrete could be successfully and efficiently crushed and reused as aggregate for fresh concrete. Therefore, finding a feasible solution to recycle or reuse concrete in Northern Cyprus, will not only reduces the cost of fresh concrete, but also contribute to environmental sustainable construction industry, by reducing the disposed waste material and unnecessary usage of landfill as well as reducing the damage to mountains, as less rocks would be needed to be separated from mountains in Northern Cyprus.

Besides since there are no strict regulations regarding waste disposal, as well as the unavailability of waste management plan which dictates a framework for waste separation and disposal to which contractors, owners and managers must stick to, there are unorganized waste disposal in majority in Northern Cyprus (figure 8 and 9). 


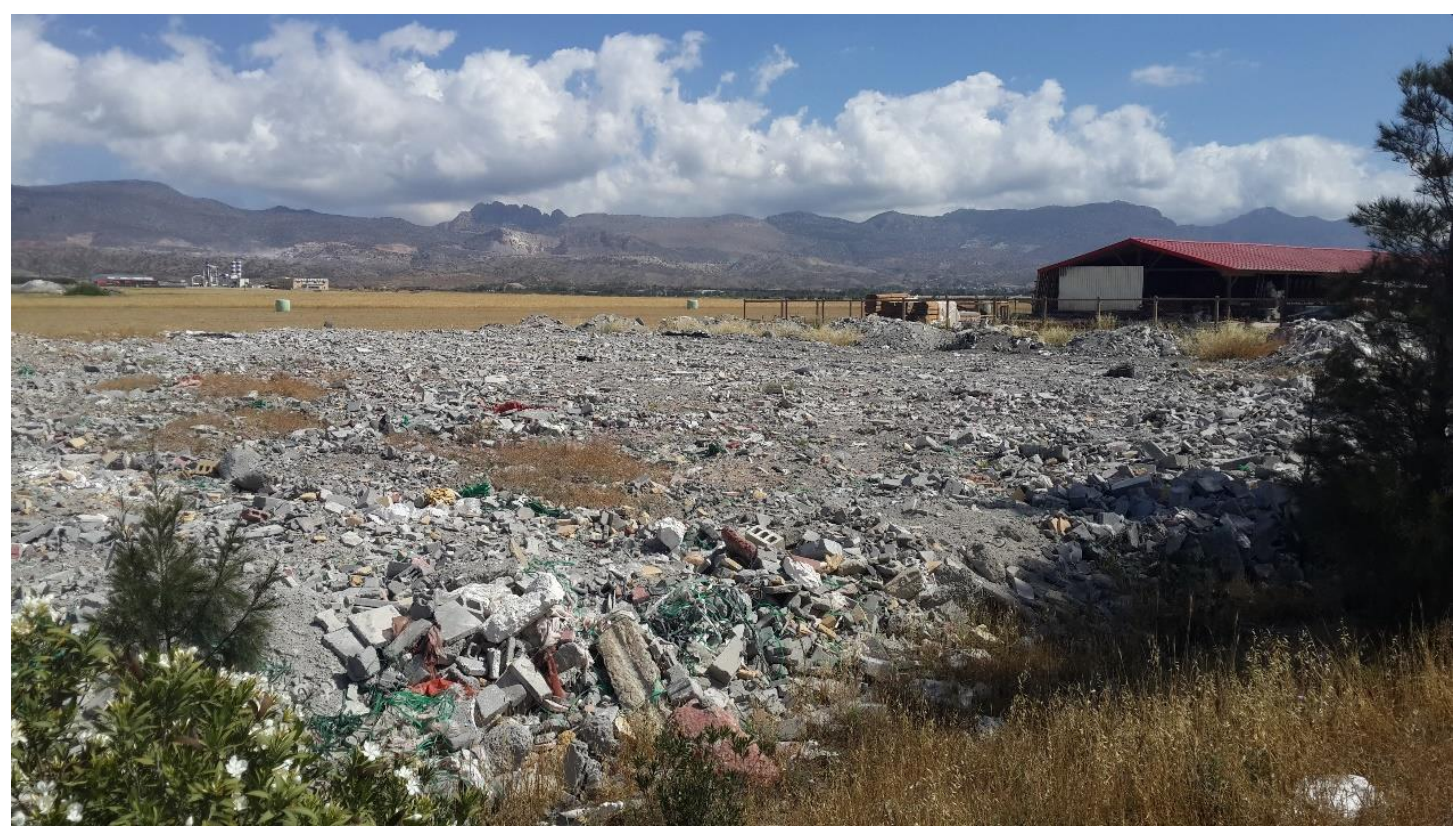

Figure 9. Unorganized waste disposal

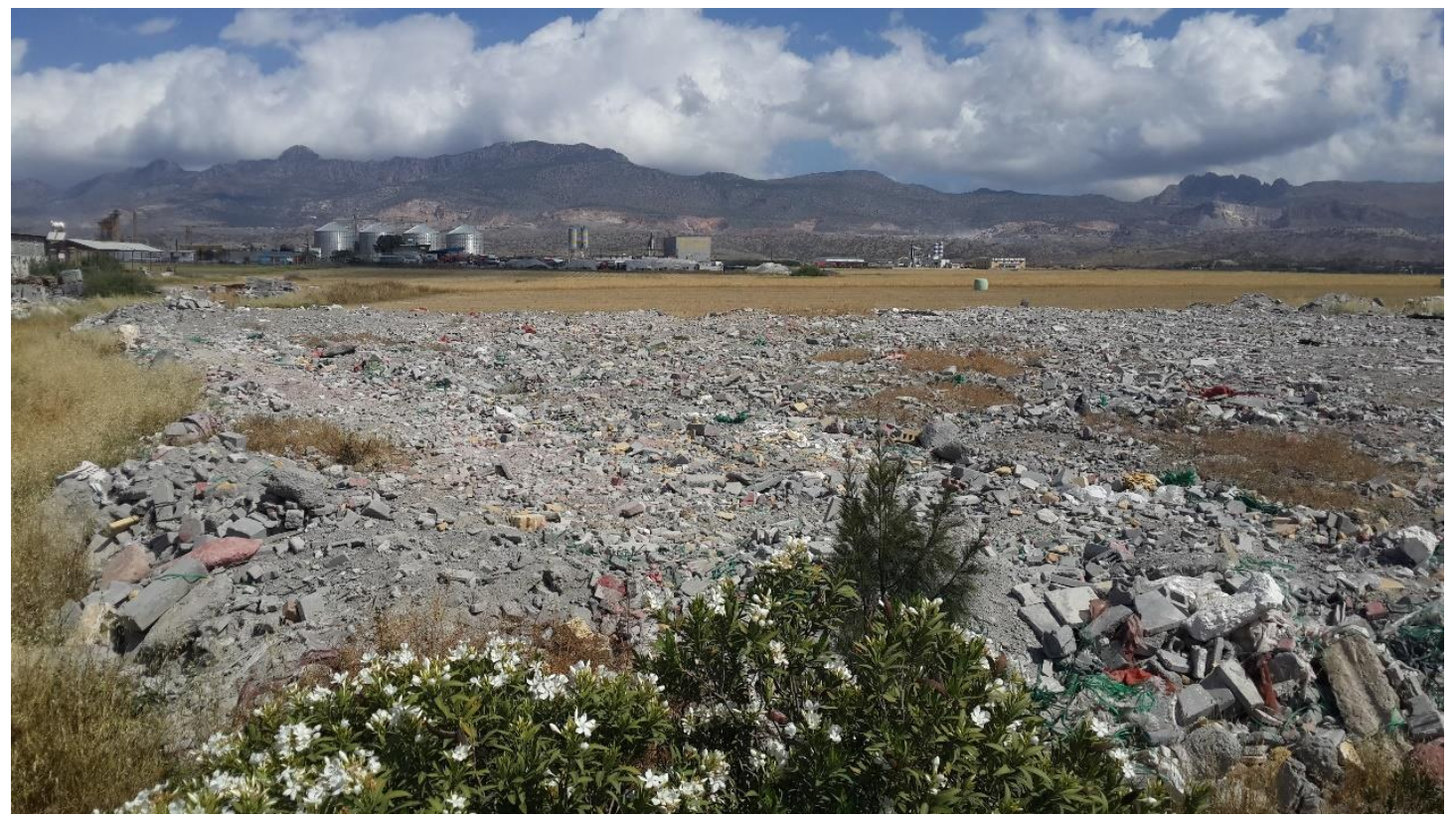

Figure 10. Unorganized waste disposal

In addition, waste materials are disposed without separation as it can be clearly seen

in figure 7 and 8 . The most important and efficient step is to separate waste materials 
as amalgamating different types of waste decrease the efficiency and quality of waste reuse and waste recycle to a considerable extent.

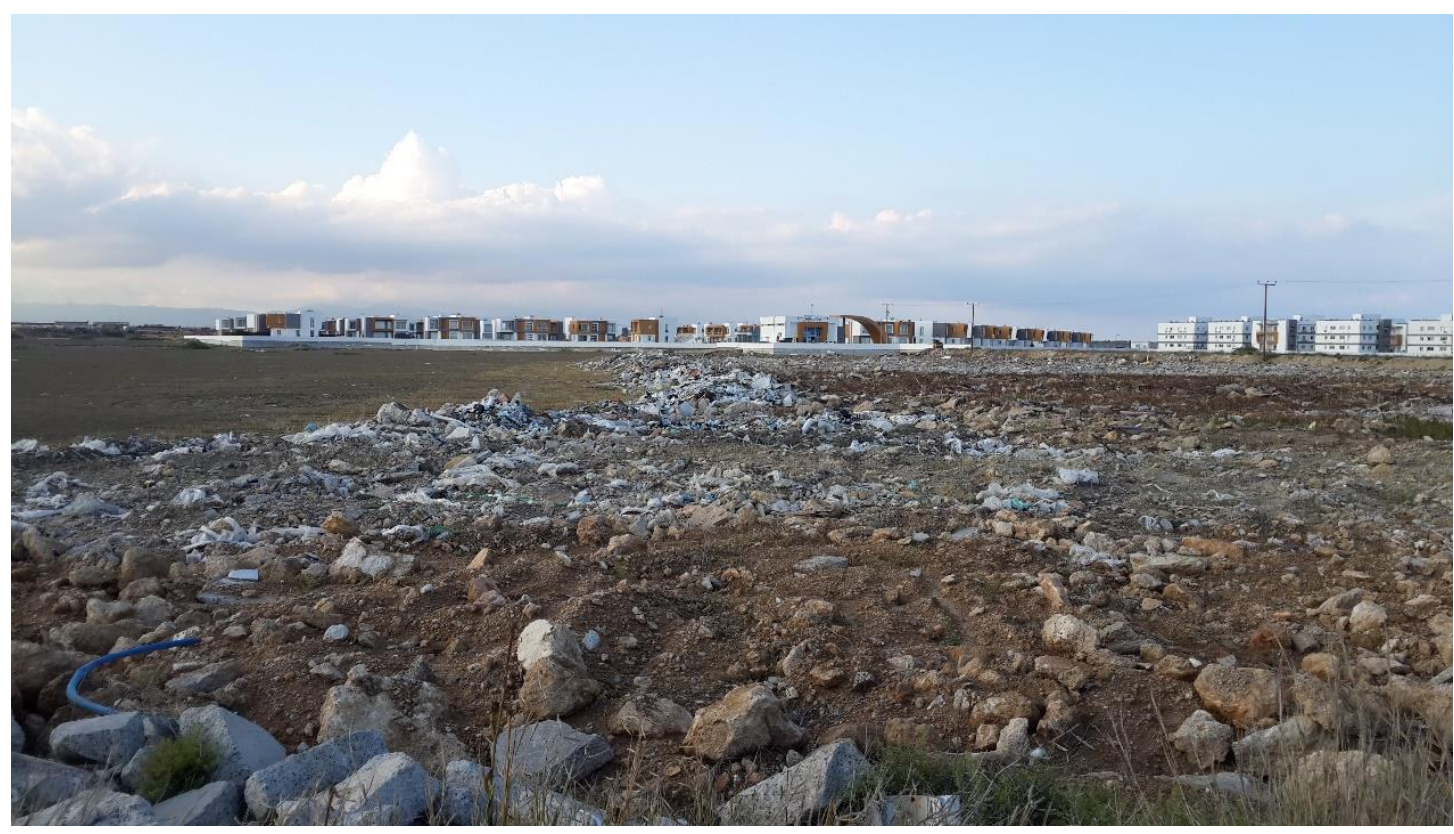

Figure 11. Mixture of different waste materials

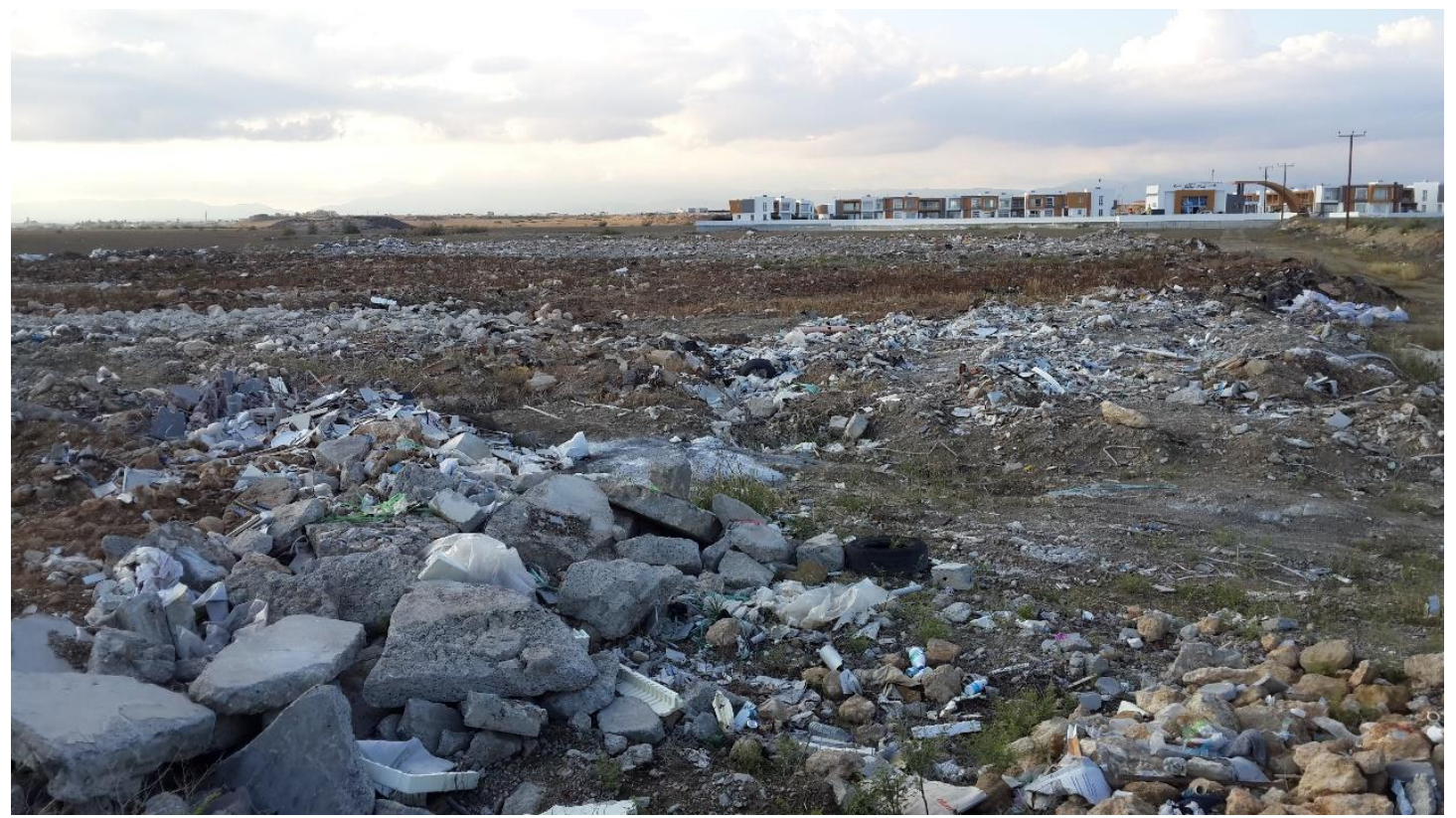

Figure 12. Mixture of different waste materials 
According to the municipal documents total annual construction area in the Northern Cyprus is calculated as $900,000-1,000,000$ square meters. Since exact area of construction in Famagusta has not been clarified, it is not possible to give a certain number. According to the below table there are amounts of important waste materials per square meter in order to calculate the amount of waste material on projects.

Table 2. CW Generated by Resource Consumption in Implementation of the CCM

\begin{tabular}{|c|c|l|l|l|l|l|}
\hline \multicolumn{3}{|c|}{ None Hazardous } & \multicolumn{3}{c|}{ Hazardous } \\
\hline Wood & $\begin{array}{c}\text { Packing } \\
\text { Carton } \\
\text { Paper }\end{array}$ & Concrete & Metal Mixed & Plastic & $\begin{array}{c}\text { Waste } \\
\text { Mix }\end{array}$ & \\
\hline 5.82243 & 0.67353 & 0.0365 & 0.08514 & 0.0506 & 0.00549 & 0.15669 \\
& & & 5 & & \\
\hline Total Construction waste $=6.89756 \mathrm{Kg} / \mathrm{m}^{2}$ & & & \\
\hline
\end{tabular}

According to above table there are annually around $6,207,804-6,897,560 \mathrm{Kg} / \mathrm{m}^{2}$ total construction waste in the Northern Cyprus. Therefore for calculation of each material's amount of waste there should be individual projects' information.

Moreover depending on the types of materials used in the building project yet, by estimating the construction and debris weight and converting it to cubic meters it will be almost possible to calculate the annual waste material in the Northern Cyprus, according to information given such as the table below: 
Table 3.Conversion of Weight to Volume in Construction and Demolition Debris (For all types of structure)

\begin{tabular}{|c|c|c|}
\hline & Volume & Weight $(\mathrm{Kg})$ \\
\hline Concrete & 1 cubic meter & 2.61 \\
\hline Rubble & 1 cubic meter & 0.9 \\
\hline Drywall & 1 cubic meter & 0.33 \\
\hline Scrap Metal & 1 cubic meter & 0.65 \\
\hline Wood Plate & $\begin{array}{l}1 \text { square meter } 1 \text { inch } \\
\text { thick }\end{array}$ & 0.19 \\
\hline Wood Plate (each) & 1 unit & $0.19-0.32$ \\
\hline Scrap Wood & 1 cubic meter & 0.2 \\
\hline
\end{tabular}

Generally calculation of the amount of construction waste material in construction projects, there should be individual information about each project and material used in the same project, to be calculated based on information such as table 2 .

\subsection{Current situation of waste management in North Cyprus}

The current situation of waste management in KKTC has below characteristics and needs to be improved according to the following declarations:

- Waste management for TRNC is not comprehensive and new legislations are required to cover the area of waste management within TRNC.

- The monitoring and enforcement procedures should be implemented and more resources must be allocated in order to control environmental pollution. 
- Solid waste management is a very complex issue in North Cyprus. Such a situation leads to inefficiencies. For example, although there are some positive sides to the waste collection system in place today, total 28 municipalities collect solid waste at their territories and the vehicles that are used to collect the waste have limited uses when it come to the joint use of space to dump the waste.

- Although there are some rural areas where waste collection is not possible, the overall collection service provided is sufficient for the population.

- The amount of waste generated and waste management data is little to nonexistent which makes it difficult to plan a management system for the island.

- Dikmen and Famagusta are in a better position compared to the other districts in terms of waste collection and disposal but there is still many areas to improve upon.

- Waste collection responsibilities have been given to the municipalities. The Environmental Protection Agency has been bestowed with the responsibilities of monitoring and control of waste management.

- $\quad$ According to legislation, waste disposal facilities must obtain a license but due to the leniency of the conditions, activities do not undergo any form of an environmental impact assessment.

- Specific uptake and removal procedures or requirements for specific waste streams are not insured 
- The Environmental Protection Agency is responsible for monitoring and controlling waste management activities. Although monitoring is done, nothing is done to comply with the regulations.

\subsection{Results of Analysis on the current situation of C\&DWM in the Northern Cyprus}

In the current study, problems, possibilities and the current situation of waste generation and waste management in Northern Cyprus and the city of Famagusta is analyzed. 20 interview sessionsis designed and carried out with random contributors to the industry from different sections and result were collected and organized.

In order to gain an analytical result about the current situation of construction waste material and management plans the results from organized data, which have been collected form the interviews are demonstrated and figures are discussed accordingly.

According to the charts generated from the interviews and surveys it can be seen from figure 12 that $30 \%$ of the result came from the government members who actually play their part in the municipality of Famagusta. Same figure goes to contactors. On the other hand, $20 \%$ of interviews were done with material providers, similar to developer construction companies totally accounted for $40 \%$ of completed sessions.

The reason behind choosing these persons was that government members, contractors, material providers and developer construction companies are 4 most important contributors to construction industry and specially, their actions and 
decisions and the way they treat designers and construction managers affect the generation of waste and the promotion of waste minimization schemes significantly.

Contributors from the municipality were engineers and environment professionals from garbage public health. In contractor section on the other hand, mostly managers and engineers in architect and civil engineering departments took part.

Considering material providers sector, quantity surveyors and managers where the dominant group of participants while for developing construction companies, architects and managers were the majority. 


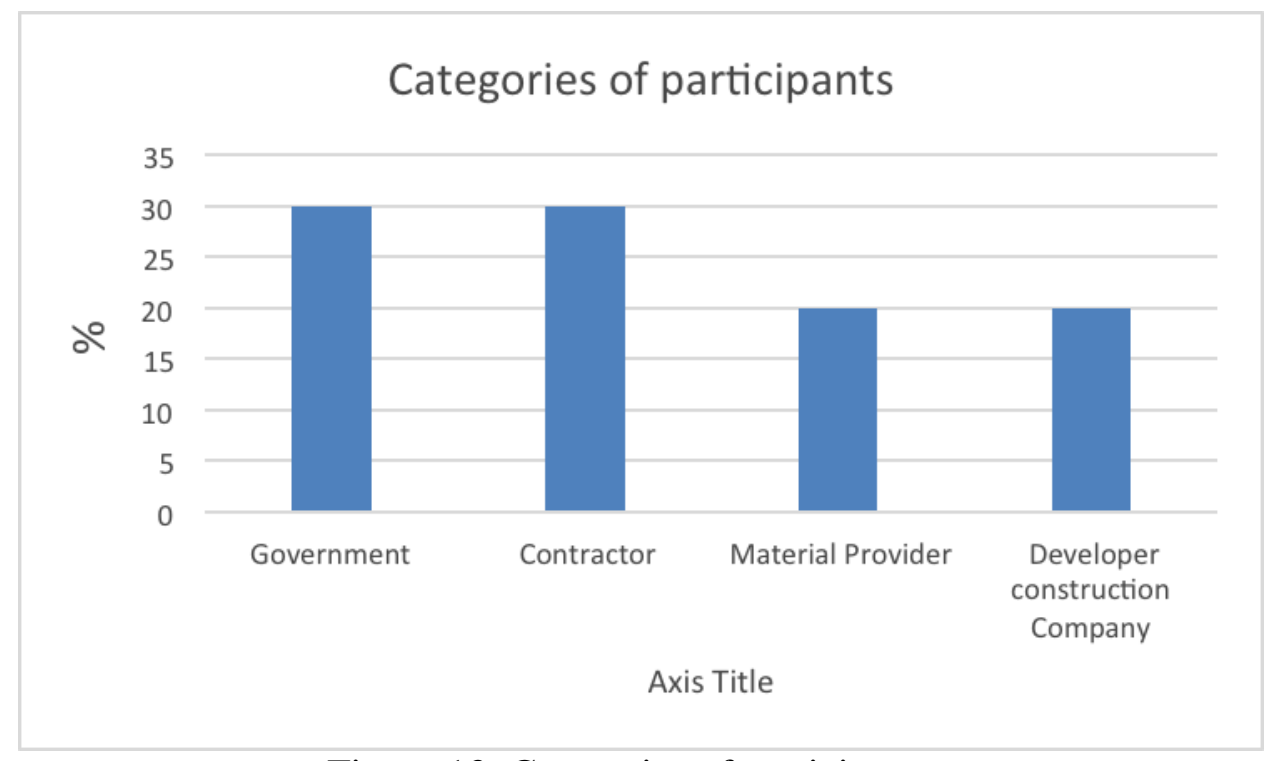

Figure 13. Categories of participants

According to figure 13, the majority of generated waste material is believed to be attributed to the construction phase, while the least percentage is attributed to the operation phase of the life-cycle of a residential unit. Operation phase is believed to generate waste material at a mediocre rate of $20 \%$.

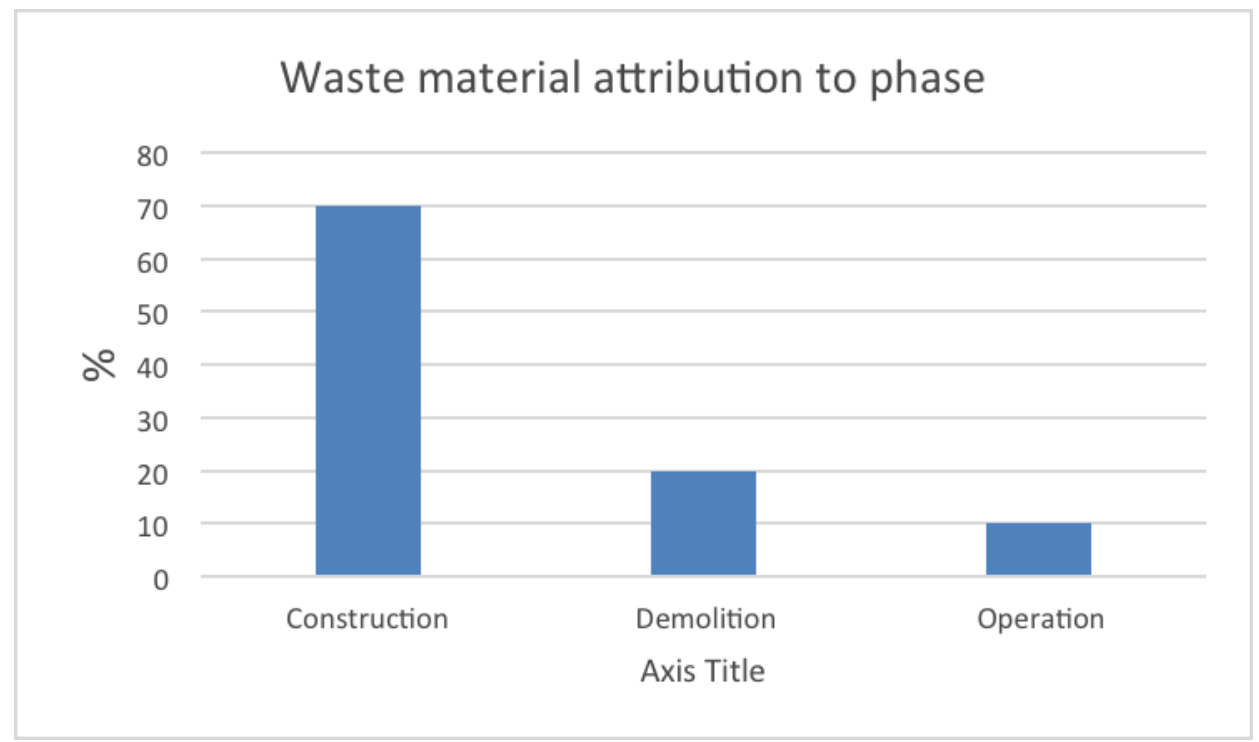

Figure 14. Waste material attribution to phase

Considering figure 14 , it is demonstrated that the majority of waste is generated as the result of concrete construction in the city of Famagusta. The minority is 
attributed to the generated waste from scaffolding, maintenance and other activities beyond the ones that are proposed.

According to the figure, it could be concluded that handling materials contributes to waste generation to a considerable extent in comparison with other factors except from concrete construction, which is normal as the majority of construction in Northern Cyprus is concrete construction. From this figure that accounts for $23 \%$ of whole generated waste, it could be concluded that an increase in the awareness level of workers can reduce the generated waste from handling materials.

Packaging ranks third in waste generation, which could be minimized by ordering materials in bulk and plan ahead for material ordering so they are transferred to the construction site in large volumes and waste generated as the result of packaging materials is minimized.

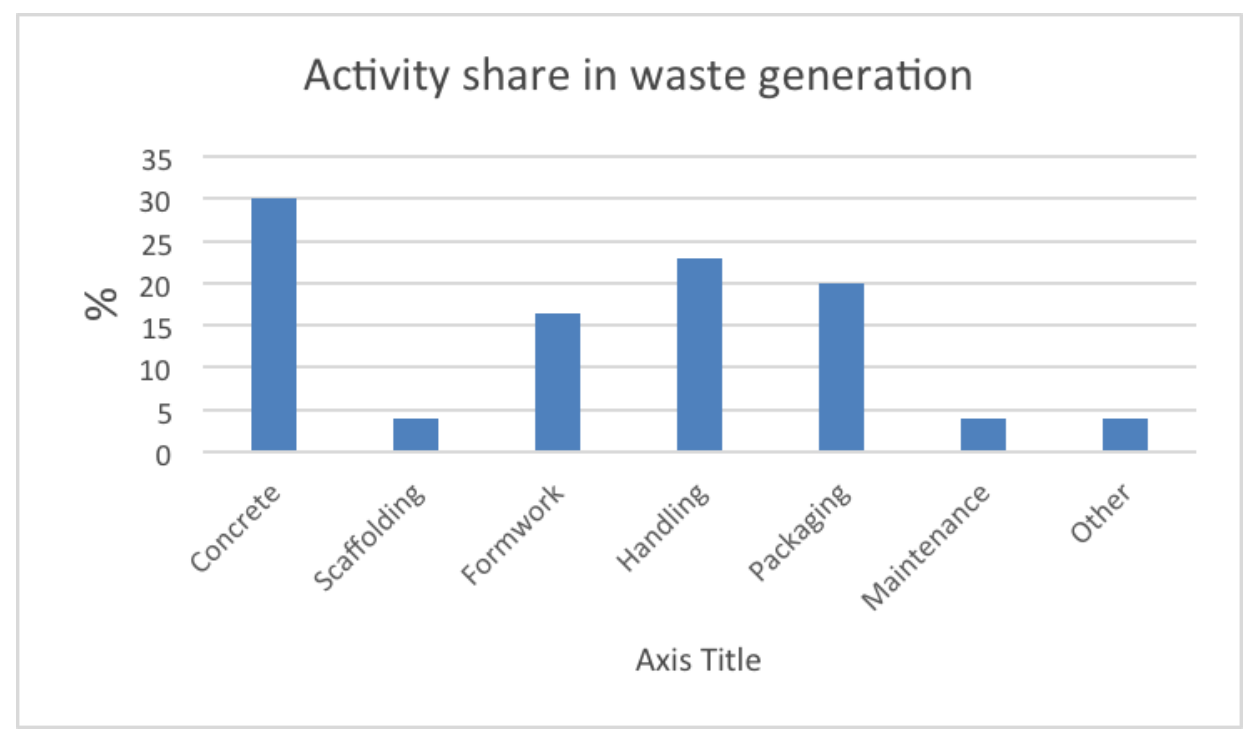

Figure 15 . Activity share in waste generation 


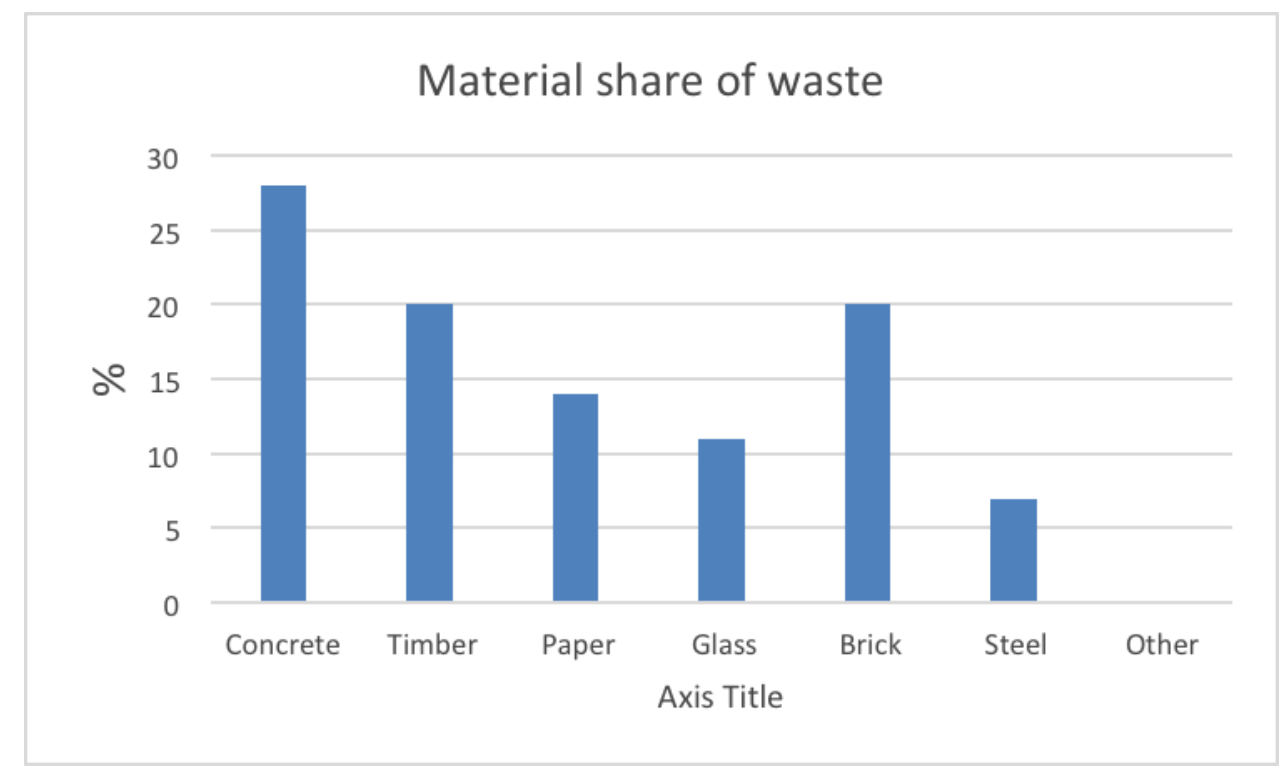

Figure 16. Material share of waste

Figure 15 demonstrates that it is unanimously believed that concrete waste is the largest volume amongst other types of waste on construction site. This fact is foreseeable as the dominant construction method is concrete construction in residential construction of Famagusta and Northern Cyprus. Brick and timber both rank second and believed to have the largest share of waste generation on the construction site.

Conversely, steel waste is believed to be minimized among well-known waste generating materials due to the fact that steel construction is not familiar in conventional residential construction in Northern Cyprus.

Some other materials such as asphalt which was suggested by DogncVeysioğlu and TahsinTranstürk, ceramic, tiles and paint are mentioned by Gökhan Noyanto are the source of waste on the site, but their contributions were considered minimal. 


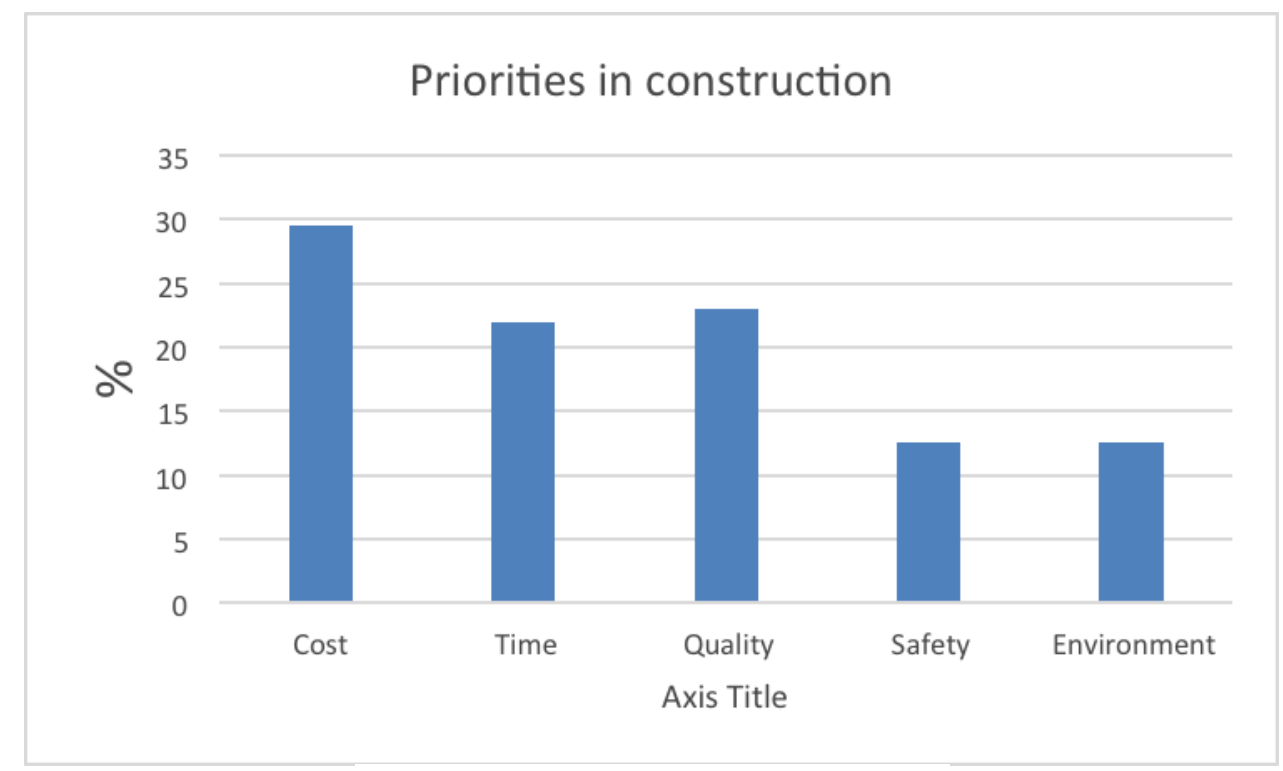

Figure 17. Priorities in construction

Figure 16 shows that in construction industry of Northern Cyprus, cost is the most important factor which is being considered while implementing a new residential project. Quality and time have a similar importance with a small advantage for quality, while safety and environment seems to attract the least attention in residential construction.

The fact derived from this figure emphasises on the environment and safety being underestimated and ignored in most of projects which is believed to be a dominant factor in waste generation. The reason behind this idea is that to prevent waste materials to be generated, not only imposes unwanted costs to the project, but also extends the completion time of the project which factors with highest priority in the present construction industry in Northern Cyprus.

Undoubtedly, trying to reduce waste materials is not encouraged by contractors, owners and engineers as each and every sectors tend to minimize cost and 
completion time of the project. This issue contributed to a surge in waste generation in the industry.

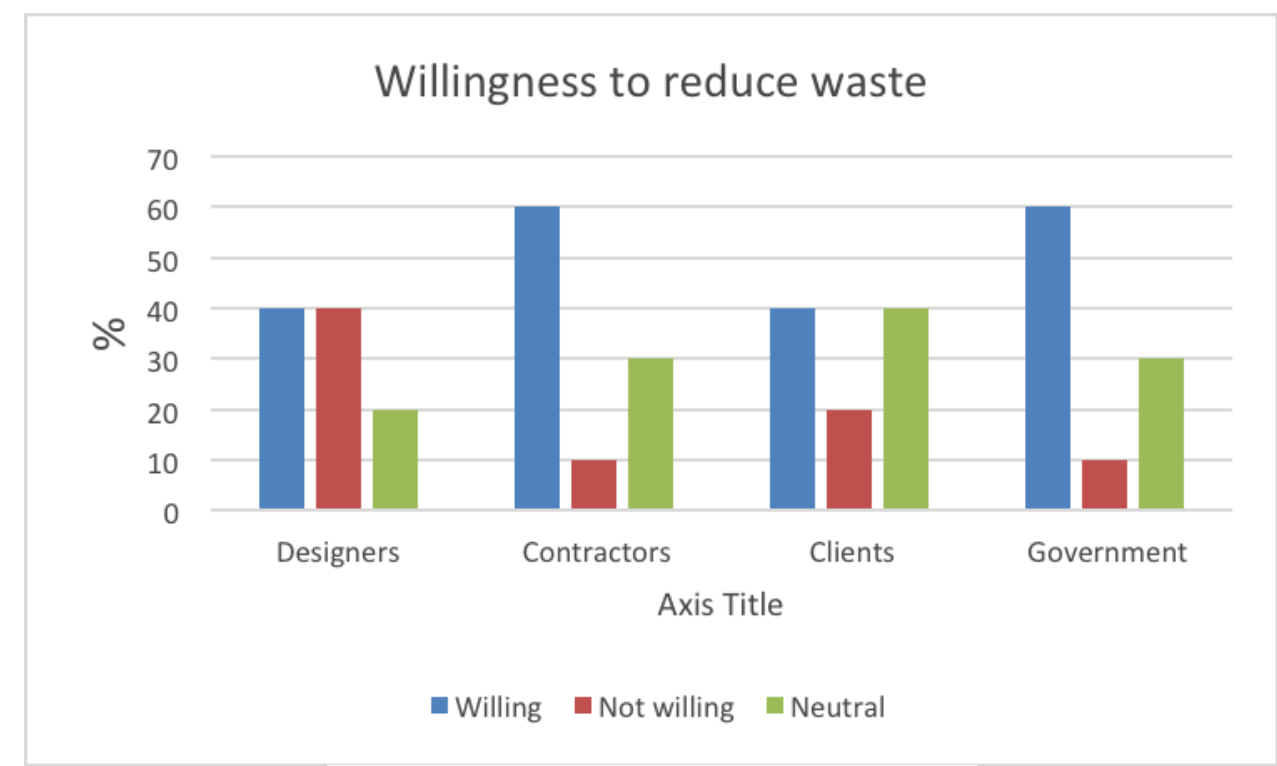

Figure 18. Willingness to reduce waste

Figure 17 illustrates the willingness of each contributor to the construction industry to reduce waste materials. It is indeed different for each party according to their concerns and interests, especially if they have to increase their monetary contributions.

It seems that government members and contractors are believed to be more willing than other contributors to reduce waste materials. Their willingness graphs are similar so it could be concluded that they have the same willingness in the issue. On the other hand, $40 \%$ of interviewees believed that designers and clients are willing to reduce waste generation in their works but, for clients, the unwillingness figure is $10 \%$ less, which implies that waste reduction is a less important priority for designers in comparison with clients. 
The fact that only $10 \%$ believed that government members are unwilling to reduce waste materials and $60 \%$ believed that they are actually willing to make changes, implies that there is a considerable potential to implement waste management plan and regulations among government members who contribute to construction industry.

According to figure 18, the most important reason behind the unwillingness to reduce the generation of waste materials reported to be lack of awareness. This is followed by cost factor and priority which could be appositive result in the potential for waste management plan implementation as it is believed that by increasing the awareness among members of the construction industry, waste could be reduced dramatically.

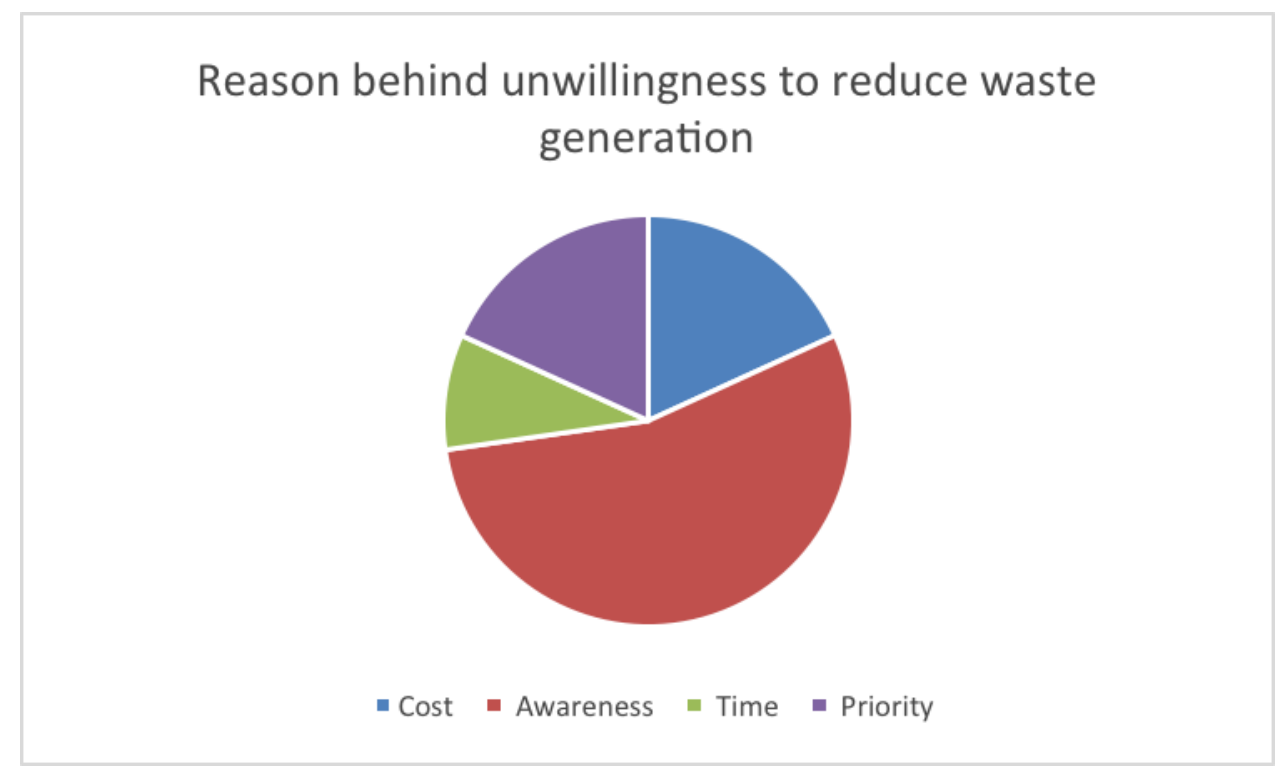

Figure 19. Reasons behind unwillingness to reduce waste generation

Another important factor in poor profile of waste reuse or recycle in Northern Cyprus is that there are no strict regulations towards waste disposal and management. This idea is confirmed by the result of interviews, which shows that $90 \%$ of interviewees believed that there are no governmental regulations towards waste management, 
waste disposal and waste reduction in the city of Famagusta. Only $10 \%$ including an environmental law (18/2012) and a municipality law (19/1995), which demonstrate that even though there are such regulations, they are not implemented seriously as the majority are unaware of their existence.

As experiences toward waste management on construction site timber was mentioned to be reused of pallets, and when divided into smaller pieces could be reused for scaffolding purposes and marble fixing supporting as mentioned by TolgaHatay. Concrete on the other hand is mentioned to be reused only for filling purposes.

Another material to be reused on the site was brick, which is used for backfilling and landfilling purposes, and steel was mentioned to be collected and exported abroad. Steel was mentioned to be capable of being sold for 400 Turkish Lira for each ton of waste material.

There were also other materials mentioned such as marble which is used as spacing in order to make stable formworks, reusing or selling for spacing purpose between iron and concrete as mentioned. Additionally, aluminium claimed to be able to be sold for 2250 Turkish Lira per ton of waste material. Besides, PVC was claimed to be able to be recycled in Alaytoy. 


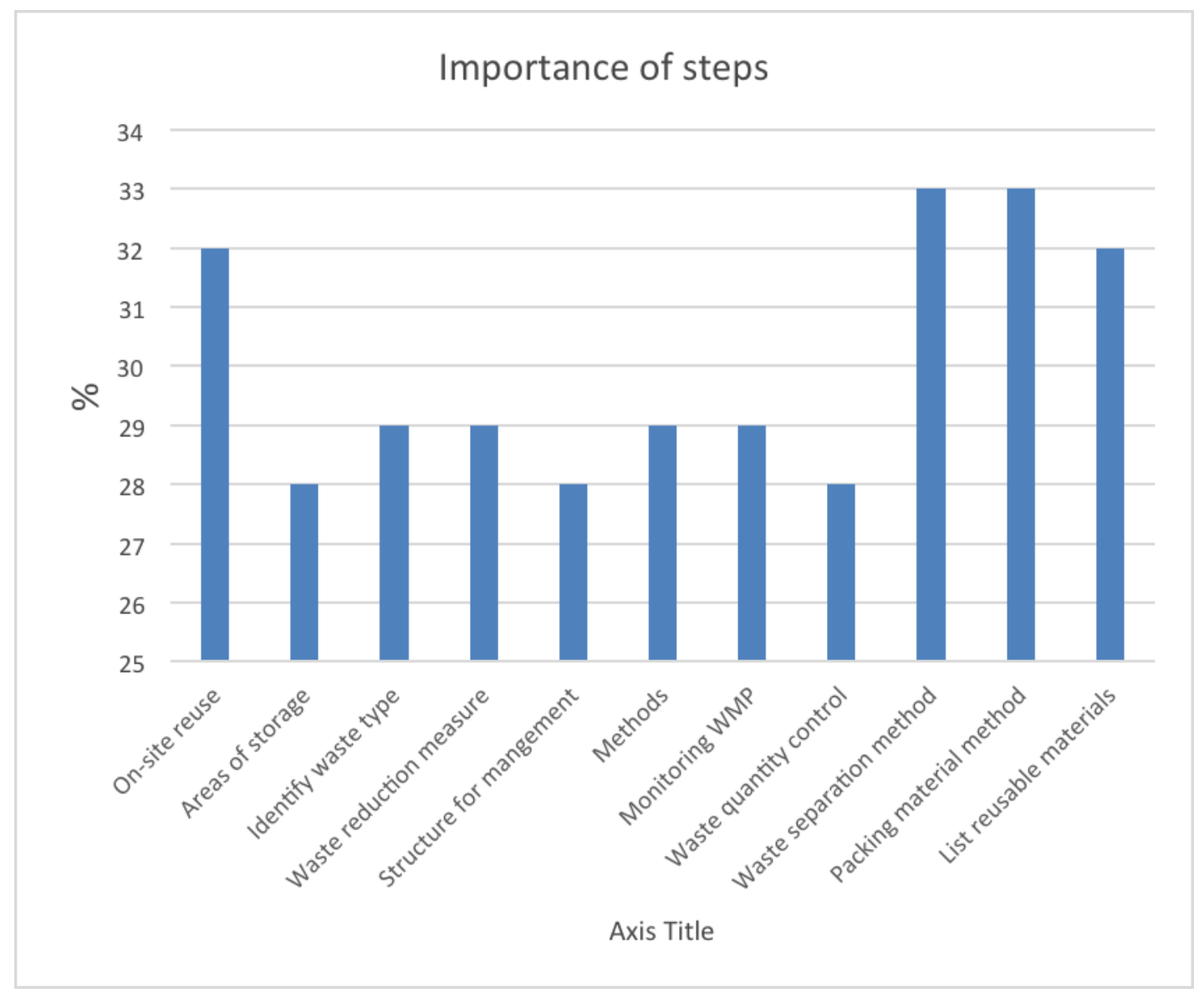

Figure 20. Importance of steps

According to figure 19, the most important statement towards the development of WMP was reported to propose a method in order to deal with packaging materials, offering methods for waste separation on the construction site, provide a list of materials, which have the potential to be recycled or reused, and offering methods by which materials could be reused or recycled immediately on the construction site.

The least important factors reported to be offering special spots for storing waste materials, developing organizational structure in order to manage generated waste and controlling the quantity of waste, which is normally being generated at a construction site. 


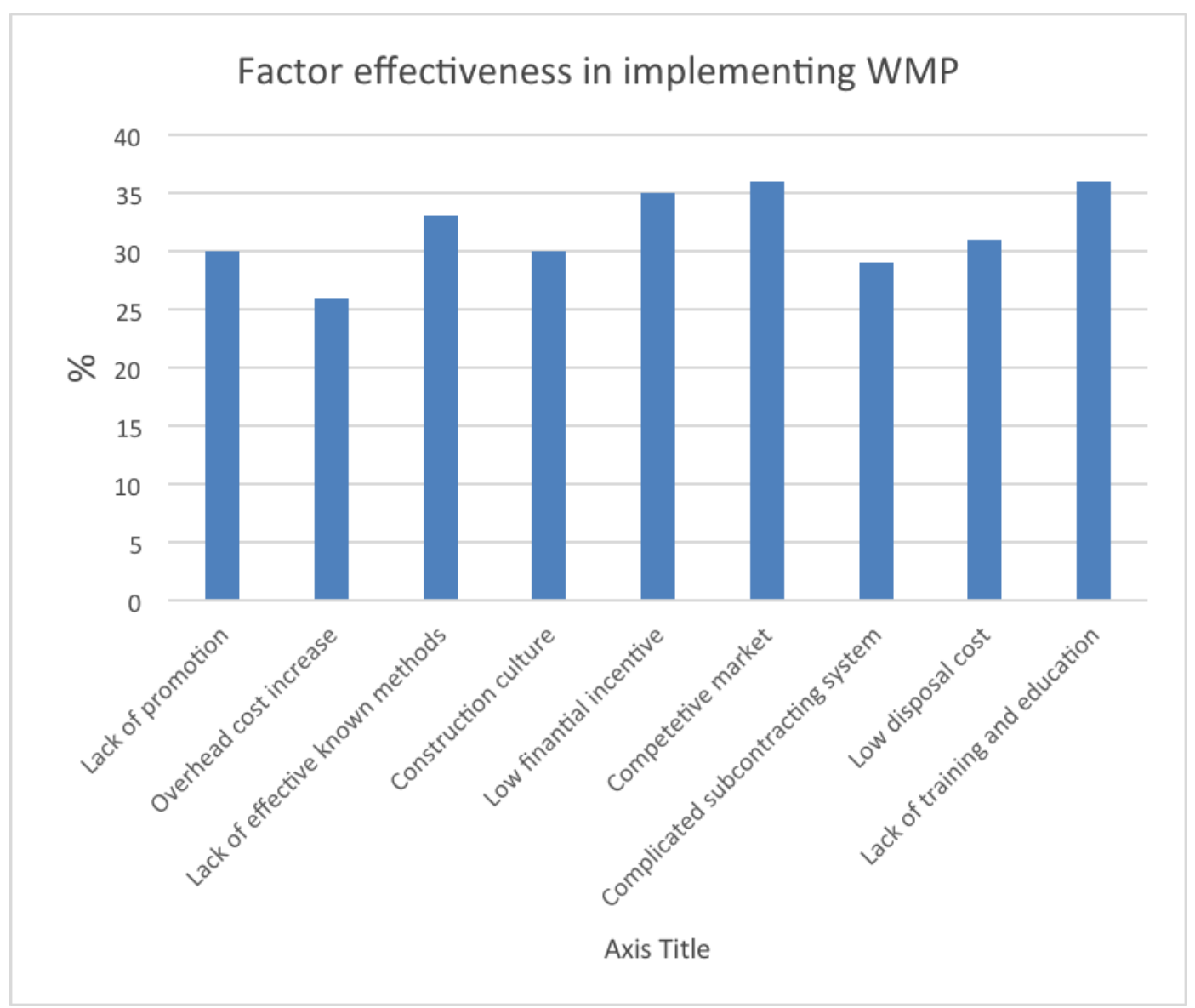

Figure 21. Factor effectiveness in implementing WMP

Limitations and possibilities of WMP implementation is analysed according to figure20, based on which lack of education, awareness and training along with unavailability of a competitive market, which is closely followed by low financial incentives. Actually, to promote a competitive market encourages the financial incentive as a consequence since higher prices would be offered to collect waste materials by different businesses that are going to reuse or recycle materials in question.

Lack of awareness about the efficiency and availability of waste management methods were also mentioned as an effective statement in WMP implementation. Actually, this is closely related to the awareness about the whole waste management 
process. By educating members of the industry, they become aware that there is actually an available market for waste materials that are inevitably generated in the construction site. Hence, they will tend to separate these materials and try to organize them so they are able to sell the materials with a higher profit, which contributes to the overall process of waste management plan implementation.

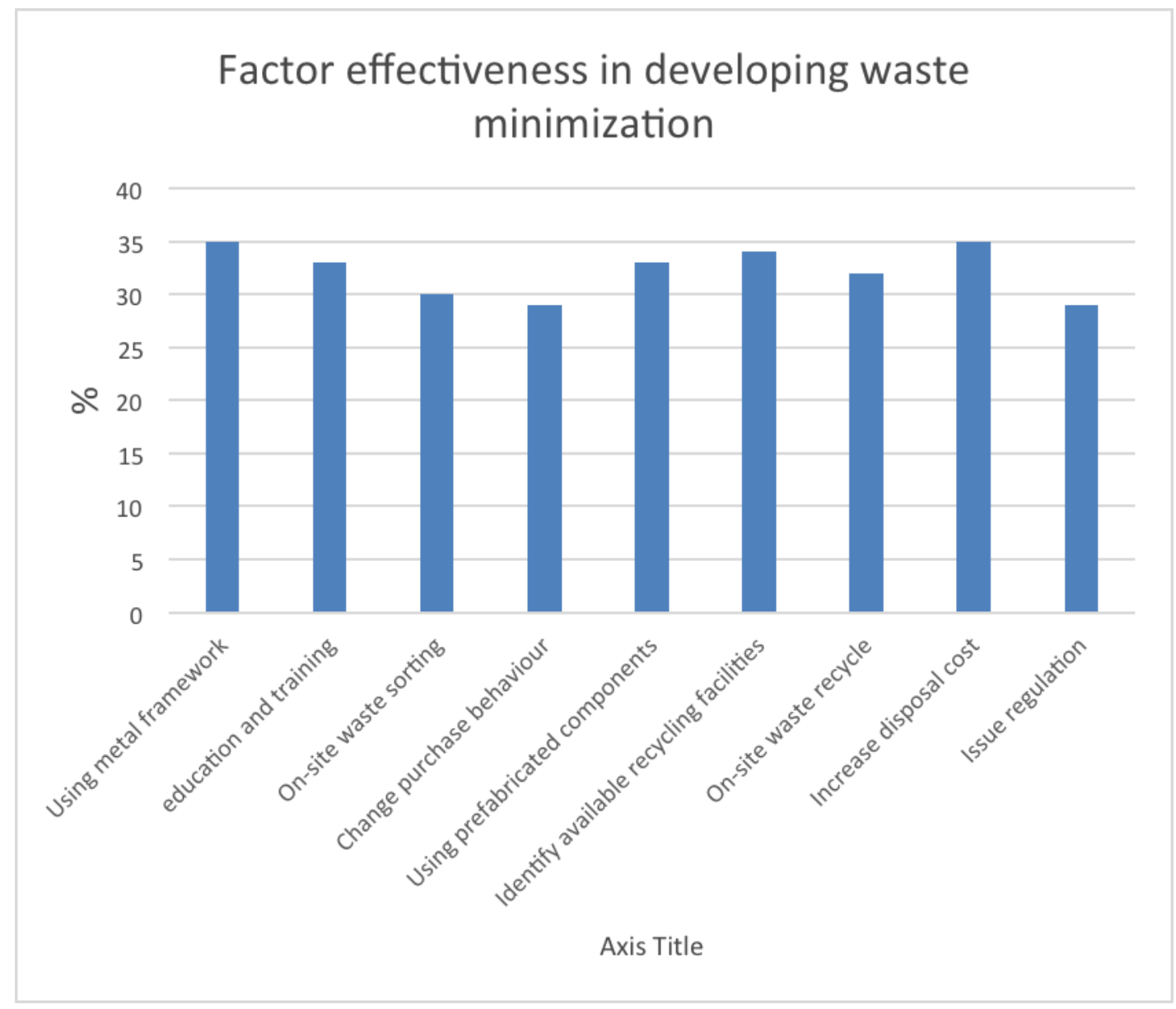

Figure 22. Factor effectiveness in developing waste minimization

According to figure 21 using metal framework considered to be an effective solution to reduce timber waste in construction sites. Timber framework is damaged more easily and possibilities to recycle wood are limited in the city and country of case study. Conversely, it is possible to sell metal waste and metal is damaged at a considerable lower rate. 
Increasing disposal cost was regarded as another effective factor in waste minimization. Actually, one of the reasons behind disposing waste materials unresponsively is that there are no apparent regulations toward waste disposal. If a relative cost is attributed to waste disposal, other alternatives that would be waste reuse or recycling and most importantly waste minimization would be considered by managers, contractors and project owners. ADD 


\section{Chapter 4}

\section{CONCLUSION}

In this study, the waste generation and waste management situation of the residential construction in Northern Cyprus the city of Famagusta is investigated. Besides, governmental limitations and restriction in order to encourage waste minimization and reducing construction waste generation was taken into account.

In addition, a comparison was made between codes and regulations of developed countries which have already implemented waste management plan and the country of case study.

Furthermore, the possibility and implacability of missing elements according to the current situation of the industry in Famagusta was analyzed. Consequently, recommendations for governmental regulations, as well as considerations at design stage and construction phase were made.

The information regarding the current situation, possibilities and limitations in residential construction industry was derived by using interviews which were done with different members of the industry. Results were then collected and the required data were derived and organized which were used as the basis for recommendations made. 
It was established that generally, in Northern Cyprus, the majority of construction waste is generated at the construction phase, in comparison with operation and demolition phase. Hence, it is recommended that limitations and regulations are focused on the construction phase of the life-cycle of the residential unit.

Concrete construction was concluded to be the major cause of waste generation, which had already been expected considering the dominant concrete construction in residential construction of Northern Cyprus. However, surprisingly it was established that more than $20 \%$ of waste is generated as the result of handling materials and almost $20 \%$ as the result of packaging. In addition, most of the generated waste material reported to be concrete which are followed by timber and brick.

Regarding to the calculation of percentages, which were presented, in the questions which were designed to be asked during the interviews, according to the number of factors, the percentage and importance of each factor could be calculated. For this, a 100 percent total figure is divided by the number of factors which is initially multiplied by the number of contributors. This is how the weighted importance for each factor is calculated. Finally, by adding up the number of weighted figures, total percentage out of 100 is calculated and presented in graphs.

According to the results of interviews, the prominent factor, which is highlighted in building a residential unit in the city of case study, is the cost of construction, which is followed by the quality and time. Safety and environment reported to be the least important factor in this area. However, it was reported that willingness to consider waste minimization is comparatively high in stakeholders of construction industry, most importantly among government members and contractors. 
One of the most important results of the aforesaid interviews was the reasons behind the unwillingness to reduce waste materials, which is reported to be the lack of awareness about the benefits and consequences. Priority and cost were also mentioned as impeding factors in waste reduction.

Regarding the available regulations and governmental codes, only $10 \%$ included some information regarding existing regulations, which were environmental law (18/2012) and a municipality law (19/1995). The fact that the majority of interviewees did not mention the aforesaid rules confirms the lack of awareness and lack of implementation force which leads to these codes be ineffective and not working.

Among all waste materials, timber, concrete and brick were mentioned as capable of being reused for filling purposes. Steel and aluminum on the other hand are being able to be sold for exporting and recycling and PVC was claimed to be recycled.

Also the most important factors in developing waste management plan are to provide a list of useful material for recycling, propose method to reduce packaging waste, propose on-site waste separation method and on-site waste reusing methods.

The impediments in developing WMP were established to be lack of awareness, unavailability of competitive market, low financial incentive and lack of effective known method for recycling or reusing materials. 
According to the observations and the analysis of the market, the following suggestions are made in order to improve the waste management situation of Northern Cyprus:

1. Codes and regulations should be focused on construction phase.

2. Concrete construction must be the focal point of limitations.

3. Standards should be issued for handling and packaging materials.

4. Increase financial incentive by subsidizing recycling and reusing activities.

5. Provide a list of useful material for recycling.

6. Propose method to reduce packaging waste

7. Propose on-site waste separation method.

8. Propose on-site waste reusing methods

9. Education, training and awareness increasing programs must be designed and carried out, in order to make members of the industry be aware of the available solutions and possibilities to reuse and recycle waste in the city, and to be informed about the consequences, advantages and disadvantages of such considerations.

10. In terms of introducing recycling technology, concrete, timber and brick should be the foremost materials to be considered.

11. Members of the industry must be informed about the existing and future governmental regulations and they should be forced to implement these rules by considering penalties for those who do not.

In addition, by comparing existing regulations in other countries and Northern Cyprus, it is suggested that the following codes are added to the regulations of construction industry in Northern Cyprus: 
1. The most important factor is considerations at the design stage, such as designing according to available materials in terms of size and applicability, and forecasting every single aspect in construction, operation and demolition in order to minimize waste materials.

2. Each project with estimated cost greater than a specific amount of money, must have waste management plan.

3. The quantity and type of waste materials which is forecasted to be produced during the project should be described.

4. For each material, there must be an action proposed for managing the waste that is going to be produced from that specific material, in order to reuse, recycle, or reduce.

5. A declaration should be included in the documents of the plan, in which client as well as the main contractor is responsible for efficient handling and proper managing of waste materials.

It is not to say that, to recycle different types of material, cutting edge technology must be in hand. In addition, to install such technology in a specific location, one should make sure that enough raw materials - in this case recyclable material - is available, to the investment pays back to all stakeholders.

According to the size of construction industry in Northern Cyprus, and the according amount of generated construction and demolition waste materials, it is suggested by the findings of this research that it is more feasible to reduce and reuse the generated construction and demolition waste on the construction site, rather than separating them and recycling them, which is an expensive choice for Northern Cyprus 
construction industry, considering the size of the whole construction throughout the year.

The major issue in the process of C\&DWM in the Northern Cyprus is to have a comprehensive plan, which covers the whole process of design and construction from upstream to downstream stages of building life-cycle. For this purpose the most important issue to be done is to create an educational plan in order to give useful information about advantages of C\&DWM programs in long term, for contractors, constructors and users. In the next stage, as it has been suggested in leading countries, there should be budgets specifically to establish pilot studies and projects to raise the knowledge about the situation of material and waste material in Northern Cyprus. By running pilot project there will be possibilities to estimate the minimum cost of waste management projects in different construction scales.

Because of many reasons including economic issues and waste generation, authorities are supposed to generate a system to record the amount of used material on the construction project. In this manner, it will be possible for designers and constructors to create an individual plan for usage of material. By performing such procedure it will be more functional to find ways to motivate individual contractors and constructors to create C\&DWM plans.

Since one of the most important issues in the process of construction is budgeting, authorities are better to regulate specific instructions and limitations for the budgets that are considered to each construction project, regarding to the scale of the project. For this reason and also for achieving other purposes it would be helpful to establish 
a supervision department in order to control and improve C\&DWM projects. Although there are existing regulations for this matter but yet there should be strict supervision on application of these regulations by individual projects.

On the other hand, the next step would be design of a specific system in which all steps of construction from the estimation of material in need, until recycling and reusing demolition waste material are organized. These way individuals can use the steps and instructions of such system accordingly.

Since the waste material is needed to be sorted out due to recycling and reusing plans, it is necessary for the responsible organizations to create plans for separation of waste material on site.

As it has been mentioned before, C\&DWM is an individual process for construction projects; and therefore plans for this purpose will be various according to variety in the nature of individual projects. Yet, authorities should perform processes to lead contractors, designers and constructors to create and perform C\&DWM plans in the Northern Cyprus. Since the natural resources of material are limited in this country and also awareness and willingness to use new materials in this country are so restricted, governmental organizations can be very effective regarding to organization of C\&DWM plans and this will take a huge step towards sustainability in architectural design and construction.

Accordingly there could be suggestions for controlling and improving waste management plans in case of methods for disposal and also to manage the procedure. 
As it will appear in the table below these sorts of suggestion might be helpful to establish proposals for construction waste management in the Northern Cyprus.

Table 4. suggestions for disposal method and handling procedure in construction projects

\begin{tabular}{|c|c|c|}
\hline Material & Disposal Method & Handling Procedure \\
\hline Concrete & $\begin{array}{l}\text { Recycle - Puget Sound } \\
\text { Concrete }\end{array}$ & $\begin{array}{l}\text { Break up any wastes or } \\
\text { mistakes and put in concrete } \\
\text { bin. Rebar OK }\end{array}$ \\
\hline Forming Boards & $\begin{array}{l}\text { Reuse as many times as } \\
\text { possible then recycle - Wood } \\
\text { Recycling NW }\end{array}$ & $\begin{array}{l}\text { Stack next to supply of new } \\
\text { form boards for reuse. } \\
\text { Recycle clean unusable } \\
\text { forms in wood recycling bin }\end{array}$ \\
\hline Clean Wood Scrap & $\begin{array}{l}\text { Scraps reused for formwork, } \\
\text { fire breaks, etc. Remaining } \\
\text { recycled - Wood Recycling } \\
\text { NW }\end{array}$ & $\begin{array}{l}\text { Stack reusable pieces next } \\
\text { to saw for reuse. Place } \\
\text { unusable clean wood in } \\
\text { wood recycling dumpster }\end{array}$ \\
\hline Scrap Metal & Recycle - Seattle Metals & $\begin{array}{l}\text { Deposit all metals in metal } \\
\text { dumpster }\end{array}$ \\
\hline Drywall & $\begin{array}{l}\text { Subcontractor will recycle } \\
\text { and submit reports to } \\
\text { recycling coordinator }\end{array}$ & $\begin{array}{l}\text { Either provide container or } \\
\text { collect in vehicle for } \\
\text { recycling }\end{array}$ \\
\hline All other wastes & Landfill - Sound Disposal & Dispose of in trash dumpster \\
\hline
\end{tabular}




\subsection{Suggestions for Future Research and Investigation}

The current investigation has been carried out within the limitations of prevailing and common construction methods. Hence, some aspects and possibilities were not able to be analysed during the research.

However, it is suggested that future studies with respect to the current literature is focused on steel construction, pre-fabricated building elements and the feasibility of bringing technology for reusing and recycling to the island.

Obviously, the dominant construction type, which is widely used on the island and consequently Famagusta, is concrete construction. Steel construction has several advantages and in terms of waste generation, the problem is alleviated as it could be possible to recycle metal to a considerable extent which is also discussed in this study. However, advantages and drawbacks of replacing steel construction could be investigated according to the most properly proposed method in the abovementioned tables.

Pre-fabricated elements are universally believed to reduce time, money and waste materials during construction. To import pre-fabricated elements however, brings several issues to the project and needs more investigation which could be carried out in future studies.

Finally, bringing reusing and recycling technology to the island, is one of the most important solutions that needs deep considerations and analysis before carrying out. The initial cost, operation and maintenance costs and revenues from such system 
should be compared with the option of waste separation and exporting it to a neighbour country and feasible solution is to be proposed in the future detailed exploration through the subject. 


\section{REFERENCES}

Al-Mutairi, N., Kartam, N., Al-Ghusain, I., \& Al-Humoud, J. (2004). Environmental management of construction and demolition waste in Kuwait. Waste Management, 1049-1059.

Austroads. (2009). Guide to Pavement Technology Part 4E: Recycled Materials. association of Australian and New Zealand road transport and traffic authorities.

Cambridge. (2008, July). Environment and Energy. Retrieved from The Cambridge Green Challenge:

http://www.environment.admin.cam.ac.uk/resources/guidancedocuments/construction-site-waste-management

CHBA. (2010). CHBA Policy Position on Construction and Demolition Waste Management and Extended Producer Responsibility. CHBA.

Edge Environment PtyLtd. (2011). Construction and Demolition Waste Guide Recycling and Re-use Across the Supply Chain. Australian Government.

Environment and Energy. (2008, July). Retrieved from The Cambrifge: Green Challange: http://www.environment.admin.cam.ac.uk/resources/guidancedocuments/construction-site-waste-management 
Hayward, S. (27, 5 2010). IBBLAW. Retrieved from The Site Waste Management Plans $\quad$ Regulations $\quad 2008: \quad$ A http://www.ibblaw.co.uk/downloads/brochures/2010-05-27-14-17-52the_site_waste_management_plans_regulations_2008.pdf

HyderConsultingPtyLtd. (2011). Management of Construction and Demolition Waste in Australia. Queensland: Department of Sustainability, Environment, Water, Population and Communities.

HynderConsulting. (2011). Construction and demolition waste status report management of construction and demolition waste in Australia. Retrieved from Australian Government Department of the Environment: http://www.environment.gov.au/resource/construction-and-demolition-wastestatus-report-management-construction-and-demolition

Kofoworola, O. F., \& Gheewala, S. H. (2009). Estimation of construction waste generation and management in Thailand. Waste Management , 731-738.

Laquatra, J., \& Pierce, M. R. (2002). Waste Managemet at the Construction Site. Cornell University.

Lu , W., Yuan, H., Li , J., Hao, J. J., Mi, X., \& Ding, Z. (2011). An empirical investigation of construction and demolition waste generation rates in Shenzhen city, South China. Waste Management, 680-687. 
Mulder, E., de Jong, T. P., \& Feenstra, L. (2007). Closed Cycle Construction: An integrated process for the separation and reuse of $C \& D$ waste. Waste Management, 1408-1415.

Napier, T. (2012, 06 03). Construction Waste Management. U.S. Army Corps of Engineers, Engineer Research and Development Center / Construction Engineering Research Laboratory. Retrieved from National Institute of Building Science.

Nunes , K., Mahler , C., Valle , R., \& Neves, C. (2007). Evaluation of investments in recycling centres for construction and demolition wastes in Brazilian municipalities. Waste Management, 1531-1540.

Osmani, M., Glass, J., \& Price, A. (2008). Architects' perspectives on construction waste reduction by design. Waste Management , 1147-1158.

PWGSC. (2012, 01 03). The Environmentally Responsible Construction and Renovation Handbook. Retrieved from Public Works and Government Services Canada: http://www.tpsgc-pwgsc.gc.ca/biens-property/gd-envcnstrctn/page-8-eng.html

Shen, L., \& Yuan, H. (2011). Trend of the research on construction and demolition waste management. Waste Management, 670-679. 
Solís-Guzmán, J., Marrero, M., Montes-Delgado, M. V., \& Ramírez-de-Arellano, A. (2009). A Spanish model for quantification and management of construction waste. Waste Management, 2542-2548.

Tam, V. W. (2008). On the effectiveness in implementing a waste-management-plan method in construction. Waste Management, 1072-1080.

UKGOV. (2008, 2 8). The Site Waste Management Plans Regulations 2008. Retrieved from Legislation.gov.yk: http://www.legislation.gov.uk/uksi/2008/314/regulation/6/made

Wang, J. Y., Touran, A., Christof, C., \& Fadlalla, H. (2004). A systems analysis tool for construction and demolition wastes management. Waste Management, 989-997. 
APENDICES 


\section{Appendix A: The Interview Form}

Construction and Demolition Waste

Name: Surname:

Company: Date:

Instructions

Please answer each question according to your experiences in your current company. For part IV, express

your idea by circling the desired value. Number 0 presents the least value while number 5 is the most

valuable figure with respect to the question asked.

Part I: General Information

Part II: Waste Material Generation

1) What is the category of your company?

a. Contractor

b. Consultant

c. Government Department

d. Waste Management

e. Environment Professional

f. Other (Please Specify)

2) What is your position in your company?

a. Engineer

b. Manager

c. Quantity Surveyor

d. Site Manager

e. Other (Please Specify)

1) To which phase of construction, the majority of waste material is attributed?

a. Construction

b. Operation 
c. Demolition

2) Please select 3 major waste sources in the construction industry of Northern Cyprus.

a. Concrete Construction

b. Scaffolding

c. Formwork

d. Waste of Material Handling

e. Waste of Packaging

f. Maintenance

g. Other (Please Specify)

3) What do you think is the widely generated waste material on-site? (Give numbers according to the volume, e.g. 1 for most important)
a. Concrete
b. Timber
c. Paper
d. Glass
e. Brick

f. Steel

g. Other (Please Specify)

1) What is the most important factor in construction of a project in Northern Cyprus? (Give numbers according to the importance, e.g. 1 for most important)
a. Cost
b. Time
c. Quality
d. Safety
e. Environment
2) To what extent do you think that designers are willing to reduce waste in Northern Cyprus? 

a. Willing
b. Neutral
c. Not Willing
3) To what extent do you think that contractors are willing to reduce waste in Northern
Cyprus?
a. Willing
b. Neutral
c. Not Willing
4) To what extent do you think that clients are willing to reduce waste in Northern Cyprus?
a. Willing
b. Neutral
c. Not Willing

5) To what extent do you think that government are willing to reduce waste in Northern

\section{Cyprus?}
a. Willing
b. Neutral
c. Not Willing

6) What do you think would be the reason behind the unwillingness to waste reduction?
a. Cost
b. Awareness
c. Time
d. Priority
e. Other (Please Specify)

7) Have you encountered any governmental regulations towards waste management and reduction in Northern Cyprus? 
a. No

b. Yes (Please Explain)

8) What is the sector which your are working in is currently doing in each of the following parts?

Part IV: Waste Management Plan Development

1- Please circle the number, according to the importance of each statement, toward the development of waste management plan.

Propose methods for on-site reuse of materials

Propose areas for waste storage

Identify different type of waste

Propose waste reduction measures

Develop organizational structure for waste management

Propose methods of processing, sorting and disposal

Monitor waste management program

Estimate quantity of different types of waste materials

Propose methods for on-site waste separation

Propose methods for dealing with packing materials

Propose list of reusable or recyclable materials

a. Waste reduction

b. Waste reuse

c. Waste recycling

9) Explain your experience toward waste reuse and recycle on-site in Northern Cyprus.

1- Timber

2- Concrete

3- Paper

4- Glass

5- Brick 
6- Steel

7- Other (Please Specify)

2- Please circle the number, according to the effectiveness of each statement in impediment of the application of waste management plan in Northern Cyprus.

Lack of promotion of waste minimization measures

01234

Increase in overhead costs

01234

Lack of well-known effective waste management methods

01234

Construction culture and behaviour

01234

Low financial incentives

01234

Competitive market

01234

Complicated subcontracting system

01234

Low disposal costs

01234

Lack of training and education

01234

1- Please circle the number, according to the effectiveness of each statement in the development of

waste minimization in Northern Cyprus.

Using metal framework

Education and training

01234

On-site sorting of construction and demolition waste materials

01234

Changing the purchase behavior

01234

Using prefabricated building components

01234

Identifying available recycling facilities

01234

On-site waste recycling operation

01234

Increase disposal cost

01234

Issue regulation and limitation toward waste minimization

01234 


\section{Appendix B: Summary of C\&D Related Legislation}

Table 4-1 Sum mary C\&D related legislation

State Source of information

New South Wales Office of Environment \& Heritage $(\mathrm{OEH})$ website, umw.environment.nsw.qov.au NSW OEH (2007) Waste Avoidance and Resource Recovery Strategy 2007 NSW Government (2006) State Plan, A New Direction for NSW NSW OEH (2010) NSW Waste Avoidance and Resource Recovery Strategy Discussion Draft: Strategic Directions and Implementation Plan 2011 - 2015 NSW OEH (2010) NSW Extended Producer Responsibility Priority Statement 2010

NSW OEH (2007) Report into the Construction and Demolition Waste Stream Audit 2000-2005

NSW Roads and Traffic Authority (RTA) Environment http://munw.rta.nsw.gov. au/environment/index.html

\begin{tabular}{|c|c|}
\hline \multirow[t]{7}{*}{ Victoria } & Sustainability Victoria website: $\underline{m w}$. sustainability.vic.gov.au \\
\hline & EPA Victoria website: $\underline{\text { unw.epa.vic.gov.au }}$ \\
\hline & Metropolitan Waste Management Group website: $\underline{\text { unw.muma.vic.gov. au }}$ \\
\hline & State Government of Victoria (2005) Towards Zero Waste Strategy \\
\hline & $\begin{array}{l}\text { Department of Sustainability and Environment (2009) Metropolitan Waste and } \\
\text { Resource Recovery Strategic Plan }\end{array}$ \\
\hline & $\begin{array}{l}\text { Sustainability Victoria (2010) Towards Zero Waste Strategy Progress Report for } \\
\text { 2008-09 }\end{array}$ \\
\hline & VicRoads Documents http://webapps. vicroads. vic. gov. au/VRNE/csdspeci.nsfl/ \\
\hline \multirow[t]{3}{*}{ Queensland } & $\begin{array}{l}\text { The Department of Environment and Resource Management (DERM) website: } \\
\text { unv.derm.gld.gov.au }\end{array}$ \\
\hline & $\begin{array}{l}\text { Department of Environment and Resource Management (2010) Queensland's } \\
\text { Waste Reduction and Recycling Strategy 2010-2020 }\end{array}$ \\
\hline & $\begin{array}{l}\text { Department of Transport and Main Roads (DTMR) Standard Specifications } \\
\text { Roads http://umw.tmr.ald gov.aul }\end{array}$ \\
\hline \multirow[t]{6}{*}{ South Australia } & Zero Waste SA website: unw.zerowaste.sa.gov.au \\
\hline & EPA South Australia website: mmv.epa.sa.gov.au \\
\hline & $\begin{array}{l}\text { Zero Waste SA (2010) South Australia's Waste Strategy 2010-2015 Consultation } \\
\text { Draft }\end{array}$ \\
\hline & South Australia Environment Protection (Waste to Resources) Policy 2010, under \\
\hline & the Environment Protection Act 1993 \\
\hline & EPA South Australia (2010) Waste Guidelines-Waste Levy Regulations \\
\hline \multirow[t]{3}{*}{ Western Australia } & Department of Environment and Conservation website: unv.dec.wa.gov.au \\
\hline & ZeroWaste WA website: unw.zerowastewa.com.au \\
\hline & $\begin{array}{l}\text { Western Australian Waste Authority (2010) Draft II Waste Strategy for Western } \\
\text { Australia March } 2010\end{array}$ \\
\hline \multirow[t]{4}{*}{ Tasmania } & $\begin{array}{l}\text { Department of Primary Industries, Parks, Water and Environment website: } \\
\text { umw.environment.tas.gov. au }\end{array}$ \\
\hline & Department of Infrastructure energy and resources website: $\underline{\text { umw.dier.tas.gov.au }}$ \\
\hline & Taswaste website: unw.taswaste.com.au \\
\hline & Department of Environment, Parks, Heritage and the Arts wnw.dpipwe.tas.gov.au \\
\hline \multirow[t]{3}{*}{ Australian Capital Territory } & $\begin{array}{l}\text { Department of the Environment, Climate Change, Energy and Water (DECCEW) } \\
\text { website: umw.environment.act.gov.au }\end{array}$ \\
\hline & $\begin{array}{l}\text { Department of Territory and Municipal Services (TAMS) website: } \\
\text { wnw.tams.act.gov.au/live/recycling-waste }\end{array}$ \\
\hline & $\begin{array}{l}\text { Department of the Environment, Climate Change, Energy and Water (2010) Draft } \\
\text { ACT Sustainable Waste Strategy 2010-2025 }\end{array}$ \\
\hline \multirow[t]{5}{*}{ Northern Territory } & Northern Territory Government website: umw.territorv2030.nt.gov.au \\
\hline & $\begin{array}{l}\text { Northern Territory Department of Natural Resources, Environment and the Arts } \\
\text { website: } \underline{m w . n t . g o v . a u / n r e t a}\end{array}$ \\
\hline & Environment Protection Authority website: unw.epa.nt.gov.au \\
\hline & The Department of the Chief Minister (2009) Territory 2030 Strategic Plan \\
\hline & 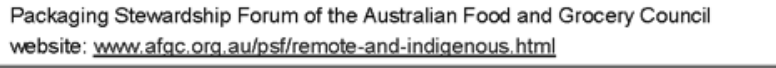 \\
\hline
\end{tabular}

